\title{
Diplomáticos y letrados en Roma al servicio de los Reyes Católicos: Francesco Vitale di Noya, Juan Ruiz de Medina y Francisco de Rojas
}

\author{
Álvaro FERNÁNDEZ DE CÓRDOVA MIRALLES \\ Universidad de Navarra \\ afdecordova@unav.es
}

\begin{abstract}
RESUMEN
Heredera de la rica tradición Trastámara, la diplomacia de los Reyes Católicos adquirió una dimensión cultural que debió desplegarse en los escenarios de su ambiciosa política europea. La sede del Papado fue un lugar privilegiado de esta actividad protagonizada por agentes que dominaban la lengua latina y poseían las habilidades literarias imprescindibles para hacerse presentes en la Roma Triumphans del Renacimiento. Este trabajo reconstruye las biografías de tres personajes-clave (Francesco Vitale di Noya, Juan Ruiz de Medina y Francisco de Rojas) que tejieron estos lazos político-culturales poniendo las bases de la diplomacia moderna.
\end{abstract}

Palabras clave: Diplomacia, mecenazgo, humanismo, literatura, embajador, Reyes Católicos, Roma, Francesco Vitale di Noya, Juan Ruiz de Medina, Francisco de Rojas.

\begin{abstract}
Inheriting the rich tradition of the House of Trastámara, the diplomacy of the Catholic Monarchs took on a cultural dimension that unfolded in the scenes of its ambitious European policy. The seat of the Papacy was a privileged place of the activity carried out by diplomatic agents who had a thorough command of the Latin language and possessed the literacy skills required for prominence in the Roma Triumphans of the Renaissance. This paper traces the biographies of three key characters (Francesco Vitale di Noya, Juan Ruiz de Medina and Francisco de Rojas) who wove such political and cultural ties, thereby laying the groundwork for modern diplomacy.
\end{abstract}

Keywords: Diplomacy, Patronage, Renaissance Humanism, Literature, Ambassador, Catholic Monarchs, Rome, Francesco Vitale di Noya, Juan Ruiz de Medina, Francisco de Rojas.

Sumario: 1. Diplomacia y literatura para una nueva monarquía 2. Francesco Vitale di Noya, un teólogo y humanista en la Corte de Fernando el Católico 3. Las empresas culturales y artísticas de Juan Ruiz de Medina 4. Entre Flandes y Roma: itinerarios europeos de Francisco de Rojas. 


\section{Diplomacia y literatura para una nueva monarquía}

Desde que Garret Mattingly definió la diplomacia moderna como una de las creaciones del Renacimiento italiano, las investigaciones no han hecho más que confirmar los vínculos que se crearon entonces entre la negociación política y el mundo de la cultura ${ }^{1}$. Esta sinergia fue posible gracias a la dimensión representativa y comunicativa de toda actividad diplomática al poner en contacto dos centros políticos dotados de sus propios modelos culturales, capaces de un mutuo entendimiento $^{2}$. El diálogo diplomático se convierte entonces en un "arte de la persuasión política", como consecuencia de un proceso de estilización del poder que concibe "el Estado como obra de arte".

Con la irrupción del humanismo, la diplomacia superó la mera trasmisión de información, convirtiéndose en un acto representativo con una dimensión cultural y ceremonial cada vez más sofisticada, que facilitaba el intercambio de bienes literarios e intelectuales en un ejercicio de enriquecimiento y comprensión recíproca ${ }^{4}$. El embajador debió adquirir entonces un particular dominio de la expresión oral, ejercitada en discursos o audiencias, una sensibilidad hacia el patrimonio cultural y artístico, un control sobre lo "escrito" a la hora de elaborar tratados, despachos o informes propios de su actividad.

En el siglo XV los reinos hispanos desarrollaron sus propias formas de representación, contando con un personal diplomático que debía adaptarse a las exigencias lingüísticas y culturales de sus respectivos destinos. A diferencia de lo que ocurría en las relaciones intrapeninsulares, las embajadas a Roma y a las asambleas conciliares tuvieron mayor incidencia en el incremento de la producción intelectual, artística y literaria ${ }^{5}$. La razón se halla en los procesos de renovación cultural y centralización administrativa que experimentaba la Curia romana por el resurgimiento de las humanae litterae y la construcción de un principado político capaz de dialogar con las monarquías modernas ${ }^{6}$.

La presencia diplomática hispana en las negociaciones del Cisma de Occidente y su participación en las reuniones conciliares posteriores, hizo posible una fecunda integración de humanismo y diplomacia en un contexto de comunicación, concesiones y colaboración con el Papado; ya sea en una dinámica de entendimiento como se aprecia en la monarquía castellana ${ }^{7}$, o salpicada de

\footnotetext{
${ }^{1}$ G. Mattingly (1970).

2 J.M. Nieto Soria (2009), pp. 15-28.

${ }^{3}$ J. Burckhardt (2004).

${ }_{5}^{4}$ M.Á. Ochoa Brun: (1989), pp. 27-63; (1995 y 2012).

${ }^{5}$ I. Beceiro Pita, (1999), pp. 79-104.

${ }^{6}$ M. Pellegrini (2010).

${ }^{7}$ Ó. Villarroel González (2010).
} 
tensiones, como sucede en la aragonesa ${ }^{8}$. Consecuencia de ello será la aparición de personalidades como Mateo Malferit, Fernando de Córdoba, Alonso de Cartagena o Rodrigo Sánchez de Arévalo, que aprovecharon sus misiones diplomáticas para cultivar, tanto el humanismo filológico cultivado en la corte napolitana de Alfonso el Magnánimo9, como el humanismo socio-político castellano que, desde la admiración de la Antigüedad, también llevó al cuidado de la expresión escrita y el redescubrimiento del pensamiento clásico ${ }^{10}$.

Esta evolución experimentó una aceleración durante el reinado de los Reyes Católicos ${ }^{11}$. En el origen del proceso está el interés de la Corona por intensificar las relaciones con el Papado para facilitar la organización de la iglesia de sus reinos, impulsar la reforma religiosa, y afrontar sus empresas políticas y descubridoras. A su condición de sede papal y centro simbólico de la Cristiandad, Roma añadía una centralidad diplomática apuntalada por las tensiones políticas que confluyeron en la península Italiana a fines del siglo $\mathrm{XV}^{12}$. El final de este vertiginoso proceso fue advertido por el rey Católico cuando a principios del siglo XVI consideraba la Urbe, no sólo como un importante centro político-religioso, sino como "plaza del mundo" que debía ser constantemente revisitada.

El primer paso hacia una diplomacia de perfil más letrado, venía dado por la necesidad de conocer los complejos mecanismos de gestión curial, como advertía Diego de Saldaña a Enrique IV en 1474, recomendando que el procurador enviado a Roma fuera "despierto en los negocyos de aquí, porque poco aprouecharía ser leal o proueido si fuese ynorante". La negociación exigía una sólida formación jurídica para tratar los asuntos eclesiásticos y un conocimiento del derecho civil para la elaboración de tratados o concertación de alianzas con príncipes y linajes del Lazio. A esta preparación "técnica" se fue añadiendo el bagaje humanístico necesario para las tareas de persuasión y propaganda regia, que sólo estaban en condiciones de desarrollar humanistas o, en su defecto, profesionales de las letras ${ }^{13}$. Sólo ellos podían componer orationes aptas para ensalzar la personalidad de sus príncipes, o explicar las motivaciones de una determinada alianza, ocultando a veces las realidades más amargas de la guerra o la tensión política.

Durante el reinado de Isabel y Fernando (1474-1516), hallamos estas habilidades entre los agentes de origen hispano o italiano que servían en la corte aragonesa (Joan Margarit, Antonio Geraldini Antonio Agustín o Francesco Vitale di Noya),

\footnotetext{
${ }^{8}$ V.Á. Álvarez Palenzuela (1996), pp. 65-89; M. Navarro Sorní (2003); M. Miglio (2012), pp. 279-296.

${ }_{9}$ A. Soria (1956); J.C. Rovira (1990).

${ }^{10}$ R.B. Tate (1970); Á. Gómez Moreno (1994), (2010), pp. 7-11; T. González Rolán; F. Hernández y P. Saquero (1994).

${ }^{11}$ J.M. Martín García (2003); (2008), pp. 487-500.

${ }^{12}$ Ch. Shaw (2007), pp. 621-638.

${ }^{13}$ G. M. Cappelli (2010), pp. 1147-1166.
} 
aunque no faltaran intelectuales castellanos (Bernardino López de Carvajal o Fernando Tello) capaces de desplegar una poderosa retórica en sus respetivas misiones diplomáticas. Otras veces era necesario elaborar epístolas para difundir noticias o mensajes exaltadores como las victorias de la campaña de Granada (Juan Ruiz de Medina), o alegatos jurídicos en defensa de los derechos al reino de Nápoles (Francisco de Rojas). El dominio del latín y de la ciencia jurídica explica que se acudiera prioritariamente a personajes de condición eclesiástica, como aconsejaba Bernardino López de Carvajal a los Reyes Católicos en 1502, pues "comúnmente son más sabios y letrados que aquí es menester". No obstante, los reyes no dejaron de recurrir a nobles laicos, como Íñigo López de Mendoza, Diego López de Haro o Garcilaso de la Vega, para dignificar sus legaciones y tratar con los príncipes italianos.

La diplomacia a fines del siglo XV exigía, además, la formación necesaria para poder incorporarse a aquellas Academias y sociedades literarias que comenzaron a frecuentar los intelectuales españoles en Roma ${ }^{14}$. En estos escenarios, la cultura y el arte ya no eran simples expresiones de ostentación, sino espacios de convergencia de intereses e intercambio de servicios, donde se formaban tupidas redes clientelares entre las casas cardenalicias y las familias baronales ${ }^{15}$. La diplomacia de los Reyes Católicos no fue insensible a este ambiente y debió desplegar todo el potencial representativo de una monarquía que pretendía desempeñar un nuevo protagonismo en el escenario político italiano ${ }^{16}$.

Desgraciadamente no siempre es fácil reconstruir el itinerario biográfico de estos personajes que tejieron la política exterior de los Reyes Católicos. Sus peripecias de las que tantas veces poseemos un conocimiento fragmentario- deben rastrearse en la documentación de archivo, las crónicas, las dedicatorias de las composiciones o las lápidas de los monumentos que promovieron. El presente trabajo ofrece las semblanzas de tres personajes clave de la diplomacia hispana. Los tres biografiados comparten su cuidada formación canónica y en ocasiones humanística, su pertenencia a los órganos de la administración monárquica, su proyección a la carrera eclesiástica, y su destino romano entre otras misiones diplomáticas: el clérigo minorita Francesco Vitale di Noya -que permanece en la Urbe entre 1477 y 1484 de manera discontinua-, el obispo Juan Ruiz de Medina -procurador permanente entre 1486-1499-, y el caballero de la orden de Calatrava Francisco de Rojas, embajador en los períodos 1485-1488 y 1501-1507. Los tres hicieron gala de una pericia avalada en las complejas misiones que se les confiaron, acompañada de una actividad literaria o artística no siempre valorada. Pensamos que la exposición

\footnotetext{
${ }^{14}$ N. Salvador Miguel (2012), pp. 47-64.

${ }^{15}$ D. Frigo (2000).

16 Á. Fernández de Córdova Miralles" (2004, 2005, 2007 a); Á. Fernández de Córdova Miralles y C. Villanueva Morte (en preparación); A.M. Oliva (2004), pp. 57-68; M.A. Visceglia (2010).
} 
biográfica es la mejor manera de apreciar la polifacética actividad de estos personajes que fecundaron las letras hispanas y barruntaron la nueva diplomacia moderna statu nascendi.

\section{Francesco Vitale di Noya, un teólogo y humanista en la corte de Fernando el Católico}

Desechadas las hipótesis que lo consideraban catalán ${ }^{17} \mathrm{o}$ aragonés ${ }^{18}$, los estudios más recientes demuestran que Francesco Vitale di Noya (c. 1415/1440-1492) había nacido en la localidad de Noicàttaro (Puglia) y procedía de la noble familia de los Noya o Noha, de origen tarentino ${ }^{19}$. Según fuentes sicilianas, ingresó en la orden de los mínimos, marchando a Francia para estudiar en la Universidad de París ${ }^{20}$. Allí se doctoró en Teología y Artes, destacando como seguidor de Duns Scoto, cuyas doctrinas mariológicas comentó en las Postillae ad Scoti mariani doctoris libros que se le atribuyen ${ }^{21}$, y le valieron la fama de celeberrimum Theologiae Artiumque Doctorem Parisiensem in Scoti doctrina ${ }^{22}$.

$\mathrm{Su}$ presencia en Barcelona se documenta el 24 de julio de 1462 como doctor artium $^{23}$. Su formación y capacitación intelectual debieron abrirle las puertas de la corte como maestre de legir e de arts al servicio del príncipe Fernando (X.1464), lo que le convierte en uno de los primeros humanistas italianos que se incorporaron al servicio del príncipe, antes incluso que Antonio Geraldini (c. 1448-1488). Dos meses después figura como secretario, formando parte del grupo de humanistas y letrados que trabajaban en la cancillería aragonesa, junto a Juan de Coloma o Joan Margarit. En 1473 se le designa como poeta laureado qui legit illustrissimo principi libros humanitatis, desarrollando una labor formativa que compartió con otros intelectuales como los catalanes mosén Miguel de Morer y mosén Antoni Vaquer, el castellano fray Hernando de Talavera, el siciliano Gregorio de Prestimarco y el citado Margarit, tal vez la persona más influyente junto al teólogo italiano en la formación política del futuro rey Católico ${ }^{24}$.

Más que como un reconocimiento honorífico en los jocs floreals barceloneses ${ }^{25}$, su nombramiento como poeta laureado debe entenderse como un galardón

${ }^{17}$ F. Fita (1873), pp. 50-51; J. Vicens Vives (1962), pp. 534-535.

${ }^{18}$ Ustárroz, ff. 256r-269r.

19 R. Pirri (1753), pp. 813 y ss; G. Misuraca (1960), pp. 31-32; G. Settani (2001); G. Quaranta (2005), pp. 53-55; Ó. Perea Rodríguez, y R. Madrid Souto (2003), pp. 745-767; Á. Fernández de Córdova Miralles (en prensa b).

${ }^{20}$ H. Enzensberger (1987), pp. 57 y 204.

${ }^{21}$ Postillae ad Scoti mariani doctoris libros (atrib.), cfr. M. Andrés Martín (1976), p. 277.

${ }^{22}$ R. Pirri (1753), pp. 813 y ss ; V. Auria (1656), p. 76.

${ }^{23}$ P. O. Kristeller, (1989), p. 97.

${ }^{24}$ Ó. Perea Rodríguez.

${ }^{25}$ F. Fita (1873), pp. 50-51. 
semejante a la coronación poética recibida por su amigo Geraldini, tras la solicitación de Juan II a Fernando redactada por el propio Noya (1.X.1469) ${ }^{26}$. Su actividad literaria ha dejado huellas en el Cancionero de Zaragoza con una composición en catalán sobre la caída de Constantinopla ${ }^{27}$, y probablemente en el Cançoner del marquès de Barbera con unos versos de temática amorosa titulados $s$ 'ils trebals que dona amor ${ }^{28}$. También se le atribuyen dos poemas en castellanorecogidos en el Cancionero General de Hernando del Castillo (1511)- que pudo componer en 1469 durante su viaje a Castilla acompañando al príncipe Fernando para contraer matrimonio con la princesa Isabel ${ }^{29}$. En el primero de éstos, Noya contesta a la pregunta de Sancho de Rojas -identificado como señor de Cavia y de Santiago de la Puebla- sobre la naturaleza del amor, mientras que en el segundo discute con Gómez Manrique -noble castellano perteneciente al círculo poético del arzobispo Alfonso Carrillo- "sobre si hubo reyes antes que caballeros", afirmando que "primero hovo en la gente / nobleza" y, por tanto, el rey sólo podía hacer noble a quien mostrara tal cualidad. Los versos de Gómez Manrique aluden a la "ciencia sobrada" del teólogo minorita que se movía con soltura por las letras latinas e italianas, "maestro muy elegante, / digno de veneración, / más que Virgilio ni Dante".

También se han atribuido a nuestro humanista los versos dedicados a Fernando con motivo de su entrada en Barcelona (3.V.1473), considerados una de sus primeras exaltaciones mesiánicas, y recompensados quizá con la canonjía gerundense solicitada para él (poeta suus) pocos días después ${ }^{30}$. Al año siguiente acompañó a Fernando en su viaje a Castilla, encargándose de la respuesta latina al discurso pronunciado por Jean de Rubempré, miembro de la legación borgoñona desplazada a Dueñas para imponer el Toisón de Oro a Fernando de Aragón ${ }^{31}$. Sus contactos literarios también se extenderían a los círculos valencianos a través de su procurador Francés de Castellví en $1479^{32}$, y a otros géneros como el homilético, al que pertenecen los sermones que se le atribuyen ${ }^{33}$.

En la década de 1470, el antiguo preceptor concluyó la traducción de De bellum Jugurtino (La guerra de Yugurta) y De coniuratione Catilinae (Catilinarias) de Cayo Crispo Salustio, obras que servían a los secretarios reales como fuente de

\footnotetext{
${ }^{26}$ M. Früh (2005), pp. 108-109.

${ }^{27}$ M. Baselga y Ramírez (1896), pp. 247-256; F. Fita (1873), pp. 50-51.

${ }^{28}$ Cançoner del marquès de Barberà; S. Martí (1997).

${ }^{29}$ J.A. de Balenchana (1882), pp. 708-709 y 717-718; T. de Azcona (1993), pp. 432-434;. Ó.

Perea Rodríguez y R. Madrid Souto (2003), II, pp. 745-767.

${ }^{30}$ J. Calmette (1902) (ed. 1977), pp. 346 y 561-562.

${ }^{31}$ A. de Palencia (1975), II, pp. 123-124.

${ }^{32}$ M. Früh (2004), pp. 110-111.

${ }^{33}$ M. Andrés Martín, (1976), I, p. 277.
} 
inspiración para apoyar argumentaciones o embellecer el latín de los documentos ${ }^{34}$; además de su traducción, el maestro ofrecía a su regio discípulo un modelo de acción política expresado en el concepto de "concordia civil" tan actual en el ambiente de la guerra civil catalana, y planteaba una serie de reflexiones sobre el pensamiento republicano o el concepto de nobleza que ya había tratado en el debate con Gómez Manrique. La obra fue impresa en Zaragoza en 1493 y, aunque se ha puesto en duda su autoría en La guerra de Yugurta, casi todos los especialistas reconocen el valor de su versión castellana de las Catilinarias. Al parecer una copia manuscrita de éstas se incorporó a la biblioteca de Ferrante de Nápoles ${ }^{35}$, y el original de La guerra de Yugurta "escrito en vitela con iluminaciones artificiosas" se conservaba en el siglo XVI en la biblioteca del duque de Villahermosa ${ }^{36}$.

Fernando apoyó la carrera eclesiástica de su maestro, iniciada en 1469 cuando Juan II solicitó al pontífice la primera abadía que vacara en Sicilia (28.XII.1469). Poco después fue nombrado protonotario apostólico, y Fernando intentó que el capítulo de la catedral de Gerona le otorgara una canonjía (8.VI.1473), con el apoyo del cardenal Rodrigo de Borja, legado entonces en la península Ibérica ${ }^{37}$. En septiembre de 1473 el príncipe solicitó en su favor el obispado de Vich, pero tuvo que plegarse a la voluntad de su padre -Juan II- que ya había pensado en Gillem Ramón de Moncada. El documento le cita con todos sus cargos cortesanos: consiliarius, preceptor, secretarius y protonotarius apostolicus. Con los encargos diplomáticos comenzaron a llover las prebendas solicitadas por el rey. En 1477 poseía un arcedianato en Siracusa que regentaba como archidiácono, aunque no falta quien niegue su disfrute por la oposición del cabildo ${ }^{38}$. En éste mismo año recibió un priorato en el monasterio zaragozano de El Pilar, pero no es seguro que lograra hacerse con el priorato en Tortosa entre 1481 y 1482. Más éxito tuvo en 1483 con una canonjía en Santiago de Compostela y otra en Ávila, que le garantizaron un sostenimiento económico estable.

A partir de 1477, Noya viajó a Roma en sucesivas ocasiones para tratar la provisión del maestrazgo de Santiago, vacante desde el fallecimiento del último titular $(1474)^{39}$. Aunque no logró culminar el encargo, encauzó el conflicto por la sede de Zaragoza entre el candidato de Juan II, su nieto Alfonso de Aragón, y el

\footnotetext{
${ }^{34}$ F. Latassa y Ortín (2004), II, pp. 374-376; J. Mª Pabón (1952), pp. 412-422; J. Rubió i Balaguer (1963), pp. 233-249; É. Rouziès (2004).

${ }^{35}$ B. Croce (2007) ( $1^{\mathrm{a}}$ ed. 1949), pp. 106-107.

${ }^{36}$ J.F.A. Ustárroz, ff. 256r-269r.

${ }^{37}$ J. Marqués Casasnovas (1963), pp. 63-64.

${ }^{38}$ Cfr. L. Wadding (1931-1964), p. 446; D.M. Sparacio (1925), p. 84 (n. XXXI); C. Cenci (1989), p. 155.

${ }^{39}$ T. de Azcona (1993), pp. 316-317.
} 
cardenal Ausias Despuig, a quien prometió beneficios compensatorios ${ }^{40}$. A principios de 1480 se enfrentó a Ludovico de Samos por ciertos beneficios concedidos por Sixto IV en la diócesis de Astorga, el monasterio benedictino de San Andres de Espinarela, y el priorato de la misma orden de María de Zebrero. Nuestro biografiado debió ganar el pleito, pues años después Inocencio VIII le confirmó tales beneficios (25.VI.1485). Mientras tanto no perdió sus contactos con sus antiguas amistades barcelonesas, como Pere Miquel Carbonell, que en 1481 solicitó su colaboración con Geraldini para valorar un libro que pensaba regalar a Gaspar de Ariño ${ }^{41}$.

En octubre de 1483 recibió credenciales como embajador en Italia y Francia con una misión relacionada con la "crisis de Ferrara" que enfrentaba a Venecia con el Papado $^{42}$. Noya se unió entonces a Gonzalo Fernández de Heredia y Joan Margarit para consolidar la alianza de sus monarcas con la Santa Sede, a la vista del fracaso de Bartolomé Veri ante la Señoría de Venecia, y es posible que se desplazase también a Nápoles con credenciales ante el rey Ferrante. En Roma debía notificar a Sixto IV y a los miembros de la Liga la prohibición del comercio con Venecia que se hizo efectiva el 29 de diciembre, y atraer a buen número de cardenales a la causa pacificadora de sus monarcas. Fernando también le pidió que ayudara al procurador castellano Gonzalo de Beteta para obtener de la Santa Sede la concesión de un indulto que le permitiera otorgar a los capellanes y cantores de la Capilla Real beneficios y dignidades en las diócesis de sus reinos (30.XII.1483).

En 1484 realizó algunos viajes a Saboya, Génova, Florencia y otros lugares de Italia para ganar aliados contra Francia. Durante estas legaciones, Noya pudo frecuentar los círculos intelectuales italianos, estrechando amistad con el filólogo y poeta florentino Ambrogio Poliziano (1454-1494), que le escribirá más tarde aludiendo a la relación del minorita con Lorenzo de Medici ${ }^{43}$. En este tiempo, Antonio Geraldini le dedicó un poema (carm. ad Ioh. 1,13) alabando su afán de quietud y su formación neoplatónica tan próxima a Marsilio Ficino (II.1483XI.1484). En este contexto pudo surgir la idea de componer una gramática latina hoy perdida- que emprendió antes de su marcha a Sicilia y era de extraordinaria calidad, según el humanista barcelonés Pere Badia $(† 1513)^{44}$.

\footnotetext{
${ }^{40}$ Para las negociaciones diplomáticas de Noya es preciso acudir a T. de Azcona (1960), pp. 92, 140 y 143-144; A. de la Torre y del Cerro (1949), I, pp. 158, 269-270, 308-311, 336337,342 , 344-346, 379-383; vol. II, 1950, pp. 29-31, 49-51, 81-83, 125-126 y 217-218; y la clarificadora síntesis de R. Madrid Souto (2006), pp. 449-456. Otra documentación inédita del embajador se conserva en Biblioteca de la Real Academia de la Historia (Madrid), Colección Salazar; Biblioteca Nacional de España (Madrid), Manuscritos.

${ }^{41}$ M. Bofarull (1865), p. 103.

${ }^{42}$ L. Suárez Fernández (1966), II, pp. 25-33, 35-45 y 47.

${ }^{43}$ M. Früh (2005), p. 110.

${ }^{44}$ M. Vilallonga (1993), pp. 35-37.
} 
Noya regresó a Roma en marzo de 1484 para obtener del papa la concesión de sisas (contribución económica del clero en el reino de Aragón), y algunas provisiones episcopales a favor de los candidatos regios. Los monarcas le recomendaban por su honestidad de vida y su célebre erudición (honestos mores et litterarum eruditionem), que Sixto IV debía conocer bien pues en los primeros meses de 1484 le eligió como miembro censor del tribunal que debía estudiar el pensamiento del sabio lulista Pedro Daguí, y esclarecer las acusaciones contra su obra Ianua Artis Magistri Raymundi Lulli. Nuestro humanista debió conocer entonces al sabio mallorquín presente en Roma, y probablemente pasaron por sus manos las cartas enviadas por Bernardo Boïl y el propio Fernando el Católico en defensa de Daguí (20.IV.1484) ${ }^{45}$. No había nada que temer. El tribunal, compuesto por reputados lulistas y escotistas como Jaime Conill, Fernando de Córdoba y el propio Noya, le exculpó de todas las acusaciones ${ }^{46}$.

No permaneció mucho tiempo más en la Urbe. Fernando quiso apartarlo del conflicto suscitado con Inocencio VIII por las sedes de Salamanca y Sevilla, recomendándole para el obispado de Cefalú, sede sufragánea de Mesina (Sicilia) otorgada por el papa el 26 de noviembre de $1484^{47}$. Noya debió abandonar Roma al año siguiente, en que se documenta su presencia en Cefalú, donde siguió recibiendo encargos relacionados con la orden de los mínimos, o el envío de ciertas cantidades de dinero para la construcción del complejo monástico de San Pietro in Montorio, promovida por los reyes en Roma.

Durante su estancia en la sede siciliana cultivó sus amistadas humanísticas, como muestra el contacto epistolar que mantuvo con Ambrogio Poliziano en 1487. Sin embargo, debió afrontar algunos conflictos jurisdiccionales con el cabildo, y ciertas dificultades en la recaudación de la bula de cruzada, cuyos retrasos le recordó el comisario de Palermo el 18 de agosto de $1491^{48}$. La resolución de estos asuntos debió motivar su viaje a Valencia en el curso del cual falleció, afectado de parálisis, el 18 de abril de $1492^{49}$. En Valencia quedó su cuerpo -tal vez en un convento franciscano-, y en Cefalú su célebre biblioteca que legó en testamento.

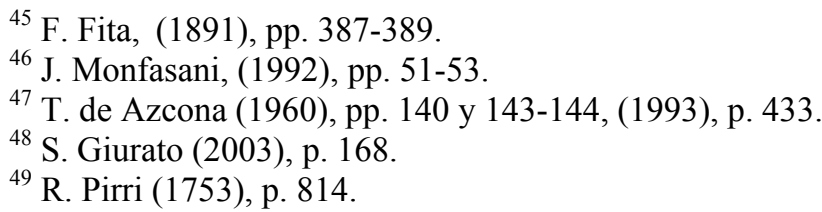




\section{Las empresas culturales y artísticas de Juan Ruiz de Medina}

Juan Ruiz de Medina (c. 1440-1507) era natural de Medina del Campo y miembro de una de las familias más encumbradas de la villa ${ }^{50}$. Marchó a Salamanca con la idea de estudiar ambos derechos, y era licenciado en Artes cuando el colegio de maestros de la Universidad le envió a Roma para negociar la expedición de ciertos documentos (5.IV.1466) ${ }^{51}$. Al año siguiente entró como bachiller canonista en el prestigioso Colegio de San Bartolomé (14.XI.1467). Se doctoró en Cánones en 1474, y más adelante obtuvo la cátedra de Prima de la Universidad de Valladolid ${ }^{52}$. Allí debió entrar en contacto con la Corte, pues en 1476 fue nombrado oidor de la Audiencia, consiliario de la provincia de León, y se incorporó al Consejo Real cubriendo la vacante del obispo de Lugo, don García de Bahamonde. Dos años después Isabel y Fernando le incluyeron en el equipo diplomático que debía negociar la paz con Francia, a donde volvió en 1479 para tratar la devolución del Rosellón y la Cerdaña. Los reyes premiaron sus servicios concediéndole en 1480 el priorato de la recién erigida colegiata de San Antolín (Medina del Campo), y en fecha incierta recibió el arcedianato de Almazán (Sigüenza) ${ }^{53}$.

En noviembre de 1480, Medina pasó a ocuparse de los asuntos de la Inquisición al ser nombrado asesor de los dos inquisidores -el maestro Miguel de Morillo y el bachiller Juan de San Martín- que instauraron en Sevilla el nuevo tribunal ${ }^{54}$. Trascurridos los sesenta días del edicto de gracia, Medina se encargó de amonestar a los cautivos y escuchar confesiones. Sin embargo, la resistencia de los conversos y la pasividad de la nobleza andaluza, llevó a los inquisidores a actuar con una dureza que indignó al cronista Pulgar, cuando escribe al cardenal Mendoza que ni Medina ni el inquisidor Diego de Merlo "harán [...] tan buenos christianos con su fuego como hizieron los obispos Don Paulo [de Santa María] y Don Alonso [de Cartagena] con su agua [bautismal]" (c. 1481). Se equivoca Ortiz de Zúñiga cuando le hace primer juez del fisco, cargo desempeñado por Fernando Yáñez de Lobón, colaborador suyo en la resolución de ciertos pleitos que se suscitaron entre Sevilla y Carmona ${ }^{55}$. Tal vez recibió entonces el beneficio de la parroquia de San

\footnotetext{
${ }^{50}$ En esta semblanza completamos los datos aportados en nuestra voz Á. Fernández de Córdova Miralles, (en prensa a); véase también el antiguo trabajo de B.S. Castellanos de Losada (1863), pp. 362-364.

${ }^{51}$ V. Beltrán de Heredia (1970), II, p. 55.

${ }^{52}$ M. Alcocer Martínez (1921), p. 412.

${ }^{53}$ G. Moraleja Pinilla (1971), p. 455.

${ }^{54}$ R. Carande y J. de M. Carriazo (1968), III, pp. 112, 129, 131, 161, 293-294 y 401; H.Ch. de Lea (1983), I, p. 200; J. Gil (2000), I, pp. 50, 67-69 y 76.

${ }^{55}$ D. Ortiz de Zúñiga (1795), I, p. 389.
} 
Pedro $^{56}$ y una canonjía en la catedral de Sevilla, donde fue nombrado prior. Durante este tiempo, Medina continuó trabajando en el Tribunal, y en 1484 sustituyó a Juan de San Martín en la reunión convocada en Sevilla por el inquisidor general Tomás de Torquemada; de ahí salieron las primeras instrucciones inquisitoriales, probablemente relacionadas con la Compilación de las instrucciones del Officio de la Santa Inquisición que se le atribuyen y fueron publicadas póstumamente en $1576^{57}$. En sus 28 artículos se regulan, entre otras cuestiones, el proceso de instalación de un nuevo tribunal y el tiempo de gracia durante el cual los inquisidores podían absolver a los judaizantes con una pena menor $^{58}$.

En 1486 los reyes le incorporaron al séquito del conde de Tendilla que debía prestar obediencia a Inocencio VIII, reconciliar al Papado con el rey de Nápoles y solicitar importantes asuntos de la Iglesia castellana. Medina iba en calidad de protonotario apostólico y "profundo conocedor del derecho canónico", con la misión de sustituir al difunto Gonzalo de Villadiego en las cuestiones inquisitoriales $^{59}$. La embajada fue un éxito y los reyes le nombraron procurador ordinario en la Curia, junto con Bernardino López de Carvajal, antiguo colector pontificio con quien aparece asociado desde $1488^{60}$. Su estancia en Roma se prolongó hasta 1499, recibiendo en estos años el obispado de Astorga (23.I.1489) que permutó por el de Badajoz (27.III.1493), y luego por el de Cartagena (20.II.1495)-, sin contar otros beneficios menores como el priorato de "Villamar" (1486-87), tal vez Villalar ${ }^{61}$.

A fines del pontificado de Inocencio VIII, Medina lidió -junto con Carvajalpor las provisiones episcopales, la obtención de las facultades para la reforma de las órdenes religiosas, la renovación de la bula de Cruzada y la consolidación del tribunal de la Inquisición ${ }^{62}$. Defendió con energía la precedencia hispana sobre los tres embajadores ingleses durante la recepción del duque de Ferrara en la Basílica de San Pedro (22.V.1487), y al año siguiente se las vio con los procuradores de

\footnotetext{
${ }^{56}$ A. Bernáldez (1962), p. 99.

${ }^{57}$ Capítulos..., ff. 59r-70v.

${ }^{58}$ M. Gamero Rojas (2010), II, p. 853.

${ }^{59}$ A. Palencia (1998), pp. LXXV-XCVII y 260; T. de Azcona (1993), p. 526; J. Burckardt (1907-1942), I, pp. 159-160.

${ }^{60}$ Sobre este importante eclesiástico G. Fragnito (1978), pp. 28-34; J. Goñi Gaztambide (1992), pp. 93-112; F. Cantatore (2007), ad indicem; I. Ianuzzi (2008), pp. 24-25; Á. Fernández de Córdova Miralles (2009), pp. 395-401.

${ }^{61}$ C. Eubel (1898-1923), II, pp. 97, 119 y 234; E. Flórez (2005), XVI, pp. 266-268.

${ }^{62}$ Temas analizados con la documentación pertinente por T. de Azcona (1960), pp. 156-157 y 162; (1993), p.759.Véanse las instrucciones de los reyes remitidas a su procurador en A. de la Torre y del Cerro (1951-1965), III-V, ad indicem, L. Suárez Fernández (1966), II, pp. 485-492.
} 
Maximiliano, reprochando al maestro de ceremonias haberles otorgado la precedencia cuando el papa aún no había confirmado como emperador al rey de Romanos (6.IV.1988) ${ }^{63}$. Su presencia también se documenta en la recepción del cardenal Pedro de Foix -aliado de los monarcas en asuntos navarros y napolitanos, y en la de Diego López de Haro, embajador extraordinario llegado a Roma para la prestación de obediencia a Alejandro $\mathrm{VI}^{64}$. Desde 1488 fue responsable con Carvajal de la construcción del complejo monástico de San Pietro in Montorio que los reyes estaban levantando en la colina del Giannicolo. Ambos se ocuparon de la administración del dinero o de la construcción de los edificios, y fue Medina quien escribió al rey en 1494 y 1495 exhortándole a destinar los fondos para completar la techumbre y el campanario de la iglesia ${ }^{65}$.

El prelado se erigió en eficaz portavoz de las victorias de la guerra de Granada, gracias a la información que le proporcionaban los reyes y amigos como el cronista Alonso de Palencia (8.I.1492) ${ }^{66}$. Cuando cayó la capital nazarí, transmitió la noticia a las ciudades de Luca, Ferrara, Siena y Módena, difundiéndola también en Milán, Francia o Basilea por medio de traducciones latinas de sus cartas ${ }^{67}$. En Roma celebró una Misa solemne de acción de gracias en la iglesia nacional de Santiago de los Españoles (19.II.1492) y organizó con Carvajal los festejos de Piazza Navona. Para entonces el prelado castellano ya estaba relacionado con humanistas romanos como Carlo Verardi, quien le dedicó una copia ricamente decorada en pergamino de la Historia Baetica (1492), o su hermano Marcelino Verardi que le dirigió palabras de agradecimiento en el prólogo de la tragicomedia Fernandus Servatus, sometida a su acerrimo iudicio, y representada y publicada en Roma en 1493 a raíz del atentado sufrido por el rey en Barcelona (7.XII.1492) ${ }^{68}$.

Tras el fallecimiento de Inocencio VIII, los procuradores de los reyes se encargaron de la vigilancia del cónclave que elegiría a Alejandro VI $\left(10\right.$. VIII.1492) ${ }^{69}$. No es posible detallar aquí la cantidad de negocios que tramitó nuestro embajador durante este pontificado en colaboración con Carvajal nombrado cardenal en 1493-, con Diego López de Haro durante la prestación de obediencia de aquel mismo año, y con Garcilaso de la Vega enviado a Roma en $1494^{70}$.

${ }^{63}$ J. Burckardt (1907-1942), I, pp. 199, 229 y 235.

${ }^{64}$ J. Burckardt (1907-1942), I, pp. 218 y 424.

${ }^{65} \mathrm{~F}$. Cantatore (2007), ad indicem.

${ }^{66}$ A. de Palencia (1998), pp. LXV y ss.

${ }^{67}$ G. Volpi (1889); P. Farenga (1993), pp. XXIX-XXX; Á. Fernández de Córdova Miralles (2005), pp. 144-169; M.D. Rincón González (2010), pp. 603-615; R. González Arévalo (2010), I, pp. 343-353.

${ }^{68}$ J.L. Gotor López (1984), p. 8.

${ }^{69}$ L. Suárez Fernández (1969), III, pp. 295-298.

${ }^{70}$ Tratamos por extenso estos asuntos en Á. Fernández de Córdova Miralles (2005). 
Aunque se ocupó preferentemente de los asuntos eclesiásticos, los tema políticos no le fueron ajenos, como muestra su participación en los acuerdos matrimoniales entre los hijos de Alfonso II de Nápoles y de Alejandro VI ${ }^{71}$. El rey alabó sus gestiones en favor de la reforma de las órdenes religiosas "porque entiendo lo fazes con la diligencia que conviene" (23.XII.1496), y al año siguiente agradeció su firme respuesta a las críticas que se habían suscitado en la Curia contra la acción reformadora de la Corona ${ }^{72}$. Medina también llevaba los asuntos de la Inquisición, y en 1498 fue nombrado doctor en la comisión creada por Alejandro VI para efectuar ciertas rehabilitaciones públicas en la iglesia de Santa María sopra Minerva (Roma), que fueron presididas por él ${ }^{73}$. Devoto de las reliquias, autenticó algunos envíos como aquella enviada al convento de Santa Catalina de Sena de la Vera (Plasencia) en 1498, y otras enviadas a la reina Isabel, incluidos dos escapularios elaborados por la beata Colomba de Rieti ${ }^{74}$.

Durante sus años romanos, mostró un especial interés por los libros iluminados: al obsequio bibliográfico de Carlo Verardi anteriormente citado, habría que añadir la venta de la preciosa Biblia (Vat. Lat. 21) que autentificó junto con Carvajal en torno a 1492 (Cod. Vat. Lat. 21) y la rica colección de incunables italianos que reunió y después legó a la catedral segoviana: de ésta se conservan actualmente quince ejemplares iluminados con ornamentación típicamente romana, de temática teológica (Summa de ecclesiae de Juan de Torquemada) artística (Architectura de Vitrubio) y canonística (Novellae super V libris Decretalium de Juan Andrea), destacando un Comentario al Decreto de Graciano que incluye un retrato de Alejandro VI semejante al célebre ejemplar umbro-romano conservado en la Biblioteca Apostólica Vaticana (Vat. Lat. 2260) ${ }^{75}$. Mientras tanto, los monarcas cuidaron sus beneficios y protegieron su cátedra en Valladolid contra los intentos de ciertos extraños a la universidad que pretendían arrebatársela (7.VII.1495) ${ }^{76}$. Sus vicarios en la sede de Cartagena también tuvieron que resolver los pleitos del provisor del anterior obispo, su compañero Carvajal, con el concejo de la ciudad por las rentas del obispado ${ }^{77}$.

Como procurador, Medina informó a los reyes de cuanto sucedía en Italia, ya se trataran de asuntos religiosos como la efímera reforma emprendida por el papa en 1497, o civiles, como los progresos de la Liga Santa y las victorias del Gran Capitán en el reino de Nápoles ${ }^{78}$. En 1498 celebró la Misa pública en sufragio del

${ }^{71}$ W. H. Woodward (2005), pp. 82-84.

${ }^{72}$ T. de Azcona, (1993), p. 742; A. de la Torre, IV, pp. 564-565.

73 Á. Fernández de Córdova Miralles (2005), pp. 696-698.

${ }^{74}$ T. de Azcona (1993), p. 390; S. Angeli (2002), p. 160.

${ }^{75}$ F. Villaseñor Sebastián (2009), pp. 239-252.

${ }^{76}$ V. Beltrán de Heredia (1972), V, p. 165.

${ }^{77}$ J. Torres Fontes (1984), pp. 341-343.

${ }^{78}$ L. Suárez Fernández (1971), IV, pp.592-596. 
príncipe Juan en la abarrotada iglesia de Santiago de los Españoles (16.I.1498) ante once cardenales y diversos embajadores ${ }^{79}$. Era el canto del cisne de una propaganda filo-hispana que once meses después enmudeció a raíz de la crisis diplomática suscitada en 1498 por el acercamiento de Alejandro VI a Francia.. El prelado castellano defendió el prestigio de sus soberanos no compareciendo en la capilla pontificia cuando se presentaban los embajadores de Luis XII ${ }^{80}$, pero la situación se hizo tan insostenible que fue necesario renovar el equipo diplomático, sustituyendo a Medina y a Garcilaso por Lorenzo Suárez de Figueroa, entonces embajador en Venecia. Nuestro prelado abandonó la Ciudad Eterna el 17.IV.1499 escoltado por el embajador Garcilaso de la Vega, los enviados extraordinarios Íñigo de Córdoba y Felipe Ponce, y más de setenta miembros de la natio hispana ${ }^{81}$.

A su llegada a la península Ibérica, se desplazó a Cartagena para jurar los estatutos de la Iglesia Catedral en el altar de Nuestra Señora de las Fiebres, actual capilla de la Concepción. Confirmó un estatuto hecho por el cabildo para la distribución de las 12 primas (4.IX.1497), y compuso los estatutos del tribunal de la Inquisición establecido en Murcia ${ }^{82}$. El 19 de marzo de 1500 realizó personalmente una visita pastoral, nombrando adjuntos a la Iglesia y suscribiendo una memoria sobre la población musulmana que había en su diócesis en 1501. Durante su mandato se hicieron cristianas las poblaciones de Alcantarilla, Alguazas, Cotillas, La Puebla y Fortuna ${ }^{83}$.

Los reyes premiaron sus servicios nombrándole presidente de la Chancillería de Valladolid (28.VI.1501) y obispo de Segovia (16.III.1502) en sustitución de Juan Arias del Villar ${ }^{84}$. En junio de 1503 tomó posesión de la sede, y realizó allí varias fundaciones con su respectiva dotación ${ }^{85}$. Tres años antes había sido nombrado abad de la iglesia colegial de San Antolín (Medina del Campo), donde inició la construcción de la cabecera y la torre de la iglesia, adquirió el patronato de la capilla mayor para convertirla en panteón familiar (14.III.1503), y donó una cruzrelicario de fina orfebrería italiana que aún se conserva. En ella aparece su blasón partido en palo, a la siniestra, cuatro bandas de plata sobre campo azur -armas del Colegio San Bartolomé de Salamanca- y, a la diestra, trece bezantes de plata,

${ }^{79}$ J. Burckardt (1907-1942), II, pp. 70-71. Sobre esta celebración romana cfr. Á. Fernández de Córdova Miralles (2005), pp. 186-187; desarrollamos estas manifestaciones festivas en Á. Fernández de Córdova y V. Calvo Fernández (en preparación).

${ }^{80}$ J. Burckardt (1907-1942), II, p. 133.

${ }^{81}$ J. Burckardt (1907-1942), II, p. 137.

${ }^{82}$ P. Díaz Cassou (1895), pp. 70-71.

${ }^{83}$ M. J. Olivares Terol (2003), p. 48.

${ }^{84}$ M. A. Varona García (1981), p. 300; Ma . de la S. Martín Postigo (1982), pp. 33-35; C. GARRIGA (1994), pp. 256 y 272.

${ }^{85}$ D. de Colmenares (1969), I, pp. 142-143; vol. II, pp. 158-159. 
también sobre campo azur ${ }^{86}$. Entre sus fundaciones se cuenta la edificación de la capilla de la Generación de Cristo - en la catedral de Sevilla-, a la que dotó de cien mil maravedíes de renta para dos capellanías, y la capilla mayor de la parroquia de nuestra Señora de la Antigua, igualmente dotada de dos capellanías. El cabildo de Badajoz también fue objeto de su generosidad al dejarle una pensión anual de 300 maravedíes sobre unas casas ${ }^{87}$.

Medina llevó con mano firme la Chancillería para desdicha de ciertos prelados como Juan de Castilla, que no lograba resolver sus pleitos con el cabildo de Salamanca por culpa de su presidente "que es el alma de los Medina e de los de mi iglesia" (15. IX.1501) ${ }^{88}$. Tras el fallecimiento de Isabel la Católica, presidió el juramento de la autoridades de Valladolid a la reina Juana (26.XI.1504), después de lo cual fue confirmado en el cargo. Murió en Segovia el 30 de enero de 1507 y cumpliendo su testamento- fue enterrado en la iglesia de San Antolín sin "sepultura alta de piedra ni monumento", sino "una piedra llana de las de Toledo para que (...) los que la vieren se conviden a rogar a Dios por mi alma" ${ }^{89}$. Años después, sus sucesores encomendaron a Juan Rodríguez, Pedro de Salamanca y colaboradores, una escultura orante en madera policromada (c. 1540) que situaron en el retablo mayor". Fue el último homenaje a este "letrado famoso", hábil diplomático y culto prelado que sirvió lealmente a la Corona en años decisivos de su historia.

\section{Entre Flandes y Roma: itinerarios europeos de Francisco de Rojas}

Perteneciente a una modesta familia asentada en Toledo a fines del siglo XIII, Francisco era el octavo hijo de Mariana de Rojas y de Alonso de Cáceres Escobar, comendador del Campo de Criptana, de la Orden de Santiago, y alcaide del castillo de Consuegra ${ }^{92}$. Aunque se ha datado su nacimiento hacia $1446^{93}$, las notas

\footnotetext{
${ }^{86}$ A. Sánchez del Barrio (2011); Civitates (2010), pp. 58-59.

${ }^{87}$ M. Blanco Contano (2007), p. 236.

${ }^{88}$ V. Beltrán de Heredia (1972), IV, p. 565.

${ }^{89} \mathrm{M}^{\mathrm{a}}$. de la S. Martín Postigo (1982), p. 34.

${ }^{90}$ J. Agapito y Revilla (1916), pp. 17-28 y ss.

${ }^{91}$ C. de Lecea (1889), p. 225.
}

92 Sobre este personaje contamos con los siguientes trabajos: P. de Rojas (1636), pp. 200r228v; F. Rodríguez Villa, 28 (1896), pp. 180-202, 295-339, 364-402 y 440-474; 29 (1896), pp. 5-69; P. López Pita (1994), pp. 99-149; Á. Fernández de Córdova Miralles (2005), pp. 95-98; J. García Oro (2009), pp. 625-720; J.M. Martín García (2013), pp. 230-232. Su rica correspondencia diplomático, no editada del todo, se encuentra diseminada entre los siguientes fondos: Biblioteca del Instituto Valencia de don Juan (Madrid), Manuscritos; Correspondencia del Gran Capitán; Biblioteca Francisco Zabálburu y Basabe (Madrid), Altamira; Archivo de la Diputación Provincial de Zaragoza (Zaragoza), Archivo de la Diputación del Reino, Alacena de Zurita; Real Academia de la Historia (Madrid), Colección 
manuscritas de un códice que le perteneció lo retrasan a 1448. Se graduó en leyes y cánones en la Universidad de Salamanca, donde adquirió fama de "gran letrado" pues "comentó libros de su facultad que tengo en mi poder, i son bien doctos, i curiosos los comentos" $"$. Uno de estos volúmenes debe ser el conservado en la Biblioteca del Instituto Valencia de don Juan (Sig. 26-I-24), que recoge, junto a piezas de interés personal, un conjunto de opúsculos jurídicos de tipo práctico atribuibles a profesores suyos (Antonio de Cornejo, Juan Alfonso de Benavente o Diego Gómez de Zamora), célebres maestros (Lope Barrientos o Alfonso de Madrigal), y otros autores clásicos (Álvaro Pelagio, Bartolo de Saxoferrato, Baldo degli Ubaldi, etc ${ }^{95}$. En 1465 Rojas recibió algún beneficio para costearse sus estudios, pero prefirió seguir la carrera de las armas participando en la guerra contra Alfonso V de Portugal y después en la guerra de Granada, donde falleció uno de sus hermanos, e hirieron a otro en la toma de Loja ${ }^{96}$. Según Fernández de Oviedo fue criado de la reina Isabel, la cual "comprendió la abilidad dese caballero, su cordura, e vido en él que era digno de ser bien empleado" "Si . Su primera misión se desarrolló en Roma ${ }^{98}$; debía lograr de Inocencio VIII la renovación de la suspendida bula de Cruzada y recomponer el litigio suscitado por la provisión de las sedes de Sevilla y Salamanca, que se habían atribuido Rodrigo de Borja y Diego Menéndez Valdés, sin permiso real ${ }^{99}$.

Rojas y Antonio Geraldini llegaron a Roma nada más fallecer el cardenal Margarit (21.XI.1484) -el principal valedor en la Curia- y, tras ocho meses de intensas negociaciones, el papa renovó la bula de Cruzada y concedió la sede de Sevilla al candidato regio ${ }^{100}$. Sin embargo, no fue Rojas quien resolvió el conflicto de las provisiones con aquellos adustos ademanes (duricies) que escandalizaron al papa, sino la intervención personal del cardenal Mendoza y la reina ${ }^{101}$. Los reyes continuaron confiándole todo tipo de negociaciones (provisiones episcopales, cuestiones financieras, permisos y privilegios de reforma, cuestiones

Salazar y Castro. Hemos empleado buena parte de la documentación inédita contenida en estos fondos en nuestro trabajo Á. Fernández de Córdova Miralles (en preparación a).

${ }^{93}$ P. de Rojas (1636), p. 200rv.; C. Gómez Menor (1963), pp. 183-197.

${ }^{94}$ P. de Rojas (1636), p. 200v.

${ }^{95}$ A. García y García (1980), pp. 361-374.

${ }^{96}$ P. de Rojas (1636), pp. 200v-201r.

${ }^{97}$ G. Fernández de Oviedo (2000), III, p. 271.

${ }^{98}$ Sobre el primer viaje de Rojas a Roma es preciso corregir la fecha errada de 1488 que figura en F. Rodríguez Villa (1896), p. 182; véanse las instrucciones reales, tramitadas antes de la partida, el 3 de noviembre de 1484 en A. de la Torre y del Cerro (1949-1966), II, p. 136.

${ }^{99}$ V. Beltrán de Heredia, 1970-1972, I-VI, ad indicem.

${ }^{100}$ T. de Azcona (1960), pp. 149-150; (1993), p. 565; A. de la Torre y del Cerro (19501966), II-V, ad índices; L. Suárez Fernández (1965-2002), II, pp. 325-331 y 378-384.

${ }^{101}$ T. de Azcona (1980), pp. 7-8. 
jurisdiccionales de su antigua universidad, etc) y la gestión con el conde de Tendilla de la concesión del Patronato Real de Granada (13.XII.1486) ${ }^{102}$. Durante este tiempo, consultó los fondos de la Biblioteca Vaticana, solicitando el Invectivarum contra medicum en que Francisco Petrarca plantea una defensa de la poesía frente a la medicina como ars meccanica, lo que supone un interesante indicio de los gustos literarios del toledano ${ }^{103}$.

Rojas debió abandonar la Ciudad Eterna entre finales de 1487 y principios de 1488, siendo relevado por Juan Ruiz de Medina y Bernardino López de Carvajal. Regresaba con el título de comendador de varias encomiendas de la Orden de Calatrava (Mestanza, Puertollano, Almodóvar del Campo y Aceca) otorgadas por los monarcas, y con una bula pontificia para la fundación del monasterio de Comendadores de la Orden de Santiago (Granada).

En febrero de 1488 los reyes le confiaron la misión de entablar una alianza con Bretaña que obligara a Carlos VIII de Francia a devolver los condados del Rosellón y la Cerdaña en los Pirineos ${ }^{104}$. Emprendió el viaje por mar desde Guipúzcoa, en compañía de Juan de Fonseca. Su labor diplomática se vio afectada por la "guerra loca" que enfrentó a bretones con franceses y el conflicto que se suscitó entre el príncipe de Orange y el mariscal de Rieux por obtener la mano de Ana de Bretaña, la poderosa heredera del ducado. Rojas actuó de mediador entre los dos partidos, pero no pudo salvaguardar la independencia de Bretaña, que acabó basculando hacia Francia. Su misión se dio por concluida en 1492, pues en los meses de octubre y noviembre lo encontramos en Toledo ocupándose de su hacienda e incorporando a su patrimonio unas casas de su madre en la colación de San Andrés.

La tercera misión de Rojas consistió en concertar la alianza con el emperador Maximiliano mediante el doble matrimonio del príncipe Juan con Margarita de Austria y el archiduque Felipe con la princesa Juana ${ }^{105}$. Fue una embajada larga, iniciada a finales de 1493, que exigió tres o cuatro viajes de Alemania a Flandes donde residían Felipe y Margarita-, y también a Francia para obtener el consentimiento de Carlos VIII a unas capitulaciones que, en el fondo, eran un tratado de amistad hispano-imperial frente a las pretensiones francesas sobre Nápoles. La sagacidad de Rojas no sólo desorientó al francés, sino que exasperó incluso al emperador por su manera de negociar "corrompiendo mis porteros y camareros para saber las cosas que yo decía"106. Finalmente se firmaron las capitulaciones que concertaban ambos matrimonios (22.I.1495), aunque hubo que

\footnotetext{
102 T. de Azcona (1960), pp. 160 y ss.

${ }^{103}$ M. Bertola (1942), p. 79.

104 J. M. Doussinague (1946), pp. 462-463; P. López Pita (1994), pp. 110-112.

105 F. Rodríguez Villa (1892), pp. 297-302; L. Suárez Fernández, y J. de M. Carriazo Arroquia (1969), t. XVII, I-II, ad indicem; L. Suárez Fernández (1965-2002), II, pp. 430431 y 435-438; IV, pp. 416-418, 517 y 591; P. López Pita, (1994), pp. 112-123.

${ }^{106}$ Duque de Berwick y de Alba (1907), p. 57.
} 
esperar al mes de noviembre para jurarlas con palabras de presente en Valladolid y en Malinas, siete meses después de publicarse la Liga Santa (31.III.1495) formada por Isabel y Fernando con el emperador y otras potencias italianas contra el ejército de Carlos VIII que acaba de invadir Italia. Según una fuente tardía, el embajador "hombre bien avisado, pero algo escaso"- olvidó completar la ropa de brocado que se le proporcionó y al desnudarse en el rito de tomar posesión del lecho de Margarita, "lleuaua tales calças que se le salía la camisa por detrás"107. Nada de esto cuenta Pedro de Rojas que, sin embargo, conservaba orgulloso aquellas calzas entre las pertenencias legadas por su antepasado ${ }^{108}$.

Durante su legación en Bretaña y en los Países Bajos, Rojas mostró interés por el arte flamenco al encargar para la reina el magnífico Libro de Horas de Isabel la Católica (Cleveland Museum of Art), atribuido a Alexander Bening, y el Breviario de Isabel la Católica (British Library) considerado una de las obras maestras de la miniatura de fines de la Edad Media ${ }^{109}$. El embajador debió adquirir este manuscrito, ya elaborado, para celebrar el doble enlace hispano-austriaco entre 1495 y 1497, incluyendo un folio (436v) con el escudo de armas de los soberanos hispanos y de los contrayentes, y en la página contigua hizo representar una miniatura de la coronación de la Virgen con sus armas rodeadas de una filacteria con su lema personal: Lux in tenebris lucet et tenebrae eam non comprehenderunt (Evang. De san Juan I, 5) ${ }^{110}$.

También mandó hacer un retablo a Hans Memling (Cincinati, Estate Fred Ziv) donde se hizo retratar como donante ante un libro de horas, y reunió un colección de "joyas y muy gran vajilla de plata"111, con aquellas lujosas arcas que aún se conservaban en su recámara en $1620^{112}$. Durante su estancia en Flandes se suscitó un pleito por ciertos dineros que los reyes le entregaron y luego reclamó la princesa Margarita ${ }^{113}$. Las cosas no se aclararon y tal vez entorpecieron la partida de la hija

107 Se trata de la colección de anécdotas y noticias verosímiles atribuida a un religioso dominico de mediados del XVI, Floreto (1948), p. 52.

${ }^{108}$ P. de Rojas (1636), p. 205rv.

109 J. Backhouse (1993); J. Yarza Luaces (1993), pp. 142-143; G. T. Clark (1997).

${ }^{110}$ Elisa Ruiz pondera el interés de Francisco de Rojas por objetivar la memoria histórica de su participación en aquel enlace matrimonial y mostrar su voluntad de servicio mediante esta exhibición heráldica y la ampulosa dedicatoria: Dive Elisabeth, Hisapniarum et Sicilie (sic) regine, etc. christianissime, potentissime, semper auguste, supreme domine sue clementissime Franciscus de Rojas, eiusdem maiestatis humilimus servus ac creatura, optime de se merens breviarium hoc ex obsequio obtulit (E. Ruiz García (2004), pp. 240243).

${ }^{111}$ G. Fernández de Oviedo (2000), III, pp 271-273.

${ }^{112}$ P. de Rojas (1636), p. 205 r.

${ }^{113}$ F. Rodríguez Villa (1896), pp. 32 y ss. 
de Maximiliano a España para contraer matrimonio con el príncipe en febrero de 1497.

Tras dos años de servicio en el Consejo Real, Rojas volvió a ser requerido a principios de 1501 para remplazar a Lorenzo Suárez de Figueroa en la embajada de Roma, confiando en su sagacidad y "mucha experiencia en los negocios de estado" "114. Debía tratar con el pontífice el reparto del reino de Nápoles entre Fernando el Católico y Luis XII, estipulado en el tratado de Chambord-Granada (XXI.1500). A pesar de lo que se ha dicho, se trató de un pacto defensivo aceptado por los reyes para evitar el conflicto en un momento en que su política internacional se veía gravemente comprometida. Esta pérdida de iniciativa se observa en sus instrucciones ordenando a Rojas negociar con el papa en los mismos términos en que lo hacía Luis XII ${ }^{115}$. El tratado suscitó los recelos del papa, temeroso de que sirviera para acometer la refformación de la Iglesia ${ }^{116}$; con todo, confirmó el reparto y otorgó la investidura del ducado de Calabria a Fernando (25.VI.1501), tras recibir los documentos por los que el rey tomaba bajo su protección a los familiares del pontífice y sus estados en el reino de Nápoles.

Durante la ocupación, Rojas recibió gruesas cantidades de dinero para el sostenimiento de las tropas destinadas en Calabria y Apulia, a través de la compañía genovesa de los Centurión o los Grimaldi ${ }^{17}$. Por él pasaban las instrucciones dirigidas a Juan Claver -en la corte napolitana- y los informes que éste remitía a los reyes en el otoño de $1501^{118}$. De nada sirvió la propuesta de Federico de Nápoles de dejar el reino en manos del rey Católico ${ }^{119}$. Siguiendo órdenes reales, Rojas se concentró en ganar partidarios en la Curia y concertar una alianza con los Colonna y la república de Génova a fines de 1502. Las cuentas de Ambrosio de Morales registran la intensa comunicación mantenida con los reyes, pues de los cinco o seis correos de 1501, se pasó a una veintena en 1502 (año de la ruptura de las hostilidades en Nápoles), hasta estabilizarse en diez correos anuales en 1503 y $1504^{120}$.

En materia eclesiástica Rojas obtuvo del papa la renovación de la bula de cruzada, la confirmación de la administración de los tres maestrazgos de Santiago, Calatrava y Alcántara (12.VI.1501), y la concesión de los diezmos para sostener la campaña contra los turcos, o cubrir las necesidades de la iglesia de Granada y de las

\footnotetext{
114 J. Zurita (1996), vol. II, libro IV, cap. XXXVIII, p. 295; Á. Fernández de Córdova Miralles (2005), pp. 425 y ss.

115 Á. Fernández de Córdova Miralles (2007 b), pp. 281-299.

${ }^{116}$ Véase el cap. 366 de la Historia del pontificado... ms. 12. Agradezco a Maria Toldrà la consulta de esta preciosa fuente cuya edición está preparando.

${ }^{117}$ F. Rodríguez Villa (1896), pp. 53-56.

118 Á. Fernández de Córdova Miralles, y C. Villanueva Morte (en preparación).

119 J. Zurita (1996) vol. II, libro IV, cap. XLIV, p. 315.

${ }^{120}$ R. de Andrés Díaz (2004), ad indicem.
} 
Indias recién descubiertas ${ }^{121}$. No tuvo tanta suerte con ciertas provisiones episcopales, ni con las bulas de reforma que los reyes le solicitaban, ordenándole no tener "con él [Alejandro VI] la blandura que teneys" y suplicar las cosas en público consistorio "porque vean todos que nos la[s] niega" (21.II.1502) ${ }^{122}$. Con todo, se mantuvieron las formas, y el embajador participó en algunas ceremonias celebradas en la Capilla Sixtina en calidad de caballero de orden militar, como se documenta en la fiesta de la Purificación de 1501 y $1502^{123}$. En mayo se llegó a una reconciliación en que se obtuvieron algunas peticiones regias a cambio de proteger a los Borja ${ }^{124}$. Rojas también se benefició obteniendo la facultad de hacer uno o más mayorazgos (15.V.1502). Cuando corrió el rumor de su posible ascenso al cardenalato, los reyes le previnieron de la "malicia con que sembraron la fama [...] por burlar de vos e para ponernos sospecha de vos que pensásemos que cabía en vuestro pensamiento que pudíades [recebir] merced de otr[o]"125.

Desde Roma, Rojas centralizó la actividad de las embajadas y consulados castellano-aragoneses instalados en Italia, manteniendo contacto con el Capitán General destinado en Nápoles -Gonzalo Fernández de Córdoba- para las cuestiones relacionadas con el reparto del reino o el abastecimiento de tropas y dinero ${ }^{126}$. En el verano de 1502 se le encomendó la formación de una Liga antifrancesa -a imitación de la Liga Santa de 1495- que uniera al Rey de Romanos, Venecia y el Papado. Salvo la alianza firmada con Génova (15.XII.1502), Rojas no logró sacar al papa y a la Señoría de su neutralidad hasta que las victorias militares del Gran Capitán inclinaron la balanza del lado español ${ }^{127}$. Para facilitar el entendimiento con el papa, el embajador tramitó la concesión del ducado de Andrea para César Borja y ofreció a Alejandro VI ciertas seguridades sobre las ciudades de Pisa, Luca y Siena ${ }^{128}$. Desgraciadamente, el fallecimiento de Alkejandro VI y la decisión de César de unirse a las tropas francesas frustró este acercamiento. El embajador emprendió entonces la negociación con los Orsini -aliados de Francia, pero más enemigos de

T. de Azcona (1960), pp. 282-284; (1993), pp. 676, 899 y 916; L. Suárez Fernández (2002), VI, pp. 85 y 194-198.

${ }^{122}$ Duque de Berwick y de Alba (1907), p. 313; P. López Pita (1994), pp. 127 y ss.

${ }^{123}$ J. Burckardt (1907-1942), II, pp. 266 y 317.

${ }^{124}$ W. H. Woodward (2005), p. 211.

${ }^{125}$ F. Rodríguez Villa (1896), p. 62.

${ }^{126}$ Para las relaciones, no exentas de tensión, entre el embajador y el Gran Capitán es preciso acudir a la correspondencia rescatada por L.I. Serrano y Pineda (1909-1912, 1921, 1943).

${ }^{127}$ L. Suárez Fernández (2002), VI, pp. 347-348 y 385-392.

${ }^{128}$ L. Suárez Fernández (2002), VI, pp. 308-309; G. de la Vega (1842), pp. 13-14; Á. Fernández de Córdova Miralles (2005), pp. 434 y ss. 
César- que cristalizó con una alianza firmada en la casa del embajador (12.X.1504) que resultó decisiva para los posteriores éxitos militares ${ }^{129}$.

Rojas fue custodio de los cónclaves que eligieron sucesivamente a Pío III y a Julio II, ocupándose de asegurar el control de la ciudad de Roma con la ayuda de los Colonna ${ }^{130}$. Apoyó la candidatura de Piccolomini contra la inclinación del Gran Capitán por el cardenal Bernardino López de Carvaja ${ }^{131}$. Fue un pontificado breve y celebrado por los monarcas, que dio paso a un nuevo cónclave más discutido en que el embajador sostuvo al cardenal Oliviero Carafa contra el parecer de Gonzalo, que lo reputaba profrancés y prefería a Giuliano della Rovere finalmente elegido como Julio II. Según Zurita, Rojas había obtenido de Carafa la promesa de recibir el capelo que della Rovere retomó para ganarse al embajador. Los reyes no quisieron aceptar aquel enjuague, pero más adelante el rey Católico trató de satisfacer los deseos del toledano.

En sintonía con Julio II, impulsó la restitución de los territorios incautados por Venecia a los Estados Pontificios bajo pretexto de actuar contra César Borja, y medió en la devolución de Forli ${ }^{132}$. En esta última operación acusó al Gran Capitán y el cardenal Carvajal de haber facilitado la evasión de César y provocar la indignación del papa en abril de 1504. Aunque el episodio se clarificó, enrareció aún más las tensas relaciones del embajador con el cardenal y con el virrey, al que acusaba de puentearle enviando agentes propios para negociar en la Curia. El embajador tampoco se libró de la reprimenda regia por debilidad en el trato con Julio II, ni de las imputaciones del Gran Capitán sobre malversación de fondos y desatención en las negociaciones con los Orsini y los Colonna (V. 1505). El toledano no perdió, sin embargo, la confianza del rey, que le concedió la ciudad de Rapolla y otras villas en Potenza (13.VII.1504), permutadas después con rentas en la Península Ibérica que nunca recibió.

Rojas no logró ganarse el apoyo del papa della Rovera, al que reprochaba su nepotismo y su carácter imprevisible ${ }^{133}$. No obstante, medió en el conflicto entre Florencia y Pisa, e intentó pacificar las tensiones entre las familias señoriales, mientras mantenía informados a los reyes de acontecimientos internacionales como la Liga de Blois (22.IX.1504). Tras la muerte de la reina Católica, exigió a los cardenales hispanos vestir cappas violatias en signo de duelo y organizó con

\footnotetext{
${ }^{129}$ Referencias a estas negociaciones en A. Giustinian (1876), I-III, ad indicem; M. Sanudo, (1879-1903), II-XIV, ad indicem; J. Zurita (1996),vol. II, libro V, cap. LXV, p. 243; W. H. Woodward (2005), p. 293.

${ }^{130}$ J. Burckardt (1907-1942), II, pp. 371 y 398-399; L. Suárez Fernández (2002), VI, p. 447. Tratamos este tema en Á. Fernández de Córdova Miralles (en prensa).

131 Á. Fernández de Córdova Miralles (en prensa).

132 Á. Fernández de Córdova Miralles (2009), pp. 11-98.

133 J. M. Doussinague (1944), pp. 538-541; Á. Fernández de Córdova Miralles (en preparación).
} 
Carvajal los solemnes funerales en la Iglesia de Santiago de los Españoles (26.II.1505), donde compareció con veinte servidores de su casa. Comenzaba entonces una nueva etapa como embjador de Fernando en pugna con el procurador de Felipe el Hermoso ${ }^{134}$. Se trataba de Antonio de Acuña, llegado a Roma en primavera con una escolta que hizo imposible su detención, ordenada por el rey Católico, justificándose por "temor que matándolo, lo que era más fáçil que prender, no le resultase a él algund ynconveniente". Buscó el auxilio del cardenal Joan de Vera y solicitó beneficios para determinados curiales que el Gran Capitán obstaculizaba para premiar a candidatos que consideraba más leales al rey. El embajador y el virrey coincidieron, sin embargo, en la defensa del reino napolitano frente a las reivindicaciones francesas, con sonadas intervenciones en la entrega del palafrén, o en altercados protocolarios protagonizados por Rojas.

Este clima de tensión se suavizó tras la firma del tratado de Blois con Luis XII de Francia (12.XI.1505) y los acuerdos de Villafáfila con Felipe el Hermoso para la gobernación de Castilla (27.VI.1506). El rey promovió entonces el nombramiento cardenalicio de su embajador junto al de Cisneros (8.XI.1505), a quien el primero había gestionado provisiones beneficiales y obtenido la facultad de testar a favor del colegio de Alcalá (24.VII.1505), recompensada con una canonjía en Toledo para un sobrino del embajador (10.II.1506) ${ }^{135}$. Aunque obtuvo el nombramiento de scriptor cancellarie (5.II.1506) ${ }^{136}$, su carrera al cardenalato se truncó en abril de 1506 por la desconfianza que enrarecía las relaciones de Fernando con Julio II. El rey intentó mejorarlas unificando la representación de su embajador con los representantes de Felipe el Hermoso, pero mantuvo un doble juego en la gestión de los asuntos en connivencia con Rojas. Éste tampoco logró disipar en mayo de 1506 los recelos del rey sobre la fidelidad del Gran Capitán, acusado de mantener relaciones con Felipe de Castilla que podían comprometer el reino del Nápoles.

Fernando el Católico contó con su embajador en el nuevo entendimiento que estableció con el papado durante su viaje a Italia. Para ello modificó la orden de permanecer en Roma, y le mandó acompañar a Julio II en su campaña contra Bolonia $^{137}$. Rojas actuó junto al arzobispo Antonio del Monte en la negociación de la entrega de la ciudad, y sostuvo una de las varas del palio usado por Julio II en su entrada solemne (14.XI.1507). Desde Nápoles, Fernando le siguió encomendando asuntos eclesiásticos, como la provisión de Santiago, la creación de las nuevas sedes de Indias, la reforma de algunos monasterios, la sucesión de fray Juan Enguerra en el cargo de inquisidor general, o la supresión de la presentación de los beneficios que eran de patronato real ${ }^{138}$. El rey le prometió futuras mercedes en

\footnotetext{
134 A. Serio (2007), II, pp. 849-862.

135 J. García Oro (1992), I, pp. 171-173.

${ }^{136}$ Th. Frenz (1989), p. 333 (n. 765).

${ }^{137}$ P. de Grassis (1886), ad indicem.

${ }^{138}$ F. Fita (1892), pp. 263-272.
} 
Castilla y, más adelante, la concesión de un oficio mayor en la Casa Real que sustituyera el frustrado capelo cardenalicio o aquel obispado de Plasencia prometido por Julio II (16.XI.1506).

Rojas se incorporó en abril a la embajada aragonesa de prestación de obediencia, junto al maestre de Montesa Bernardo Despuig, Antonio Agustín y Jerónimo de Vich (30.IV.1507) ${ }^{139}$. Compareció en la audiencia con una "ropa de ras negro enforrada de martas e con una buena cadena", defendiendo su segundo puesto en la legación frente a los intentos del maestro de ceremonias de relegarle al último lugar, como era habitual en estos actos. Durante la embajada debió negociar la concesión del capelo a Cisneros, la frustrada investidura de Nápoles, el patronato sobre los beneficios del reino, la revocación de ciertas habilitaciones concedidas por la Santa Sede en prejuicio de la Inquisición, y la concesión de los documentos para actuar contra los clérigos coronados ${ }^{140}$. El embajador permaneció en Roma hasta el mes de junio en que probablemente volvió en las galeras del rey Católico, cediendo a Jerónimo de Vich su puesto en la embajada romana..

A su regreso a la Península Ibérica, se instaló en Toledo para organizar su casa y hacienda. En 1507 adquirió la villa de Layos (Toledo) a los sucesores del adelantado Juan Carrillo, y en 1513 instituyó dos mayorazgos en sus herederos uno en Móstoles y otro en Layos- con los permisos real y pontificio ${ }^{141}$. Dos años después recibió el nombramiento de scutifer (24.VII.1515) ${ }^{142}$, compró dos tercias partes de la dehesa de El Castañar y mandó construir la cabecera y dos capillas laterales de la parroquia de San Andrés de Toledo ${ }^{143}$. La más deatacada es la Capilla de la Epifanía, y fundó antes de 1501 y comenzó a construirse tres años después como panteón familiar para entierro de sus padres, el suyo y el de otros familiares. Desde Roma Francisco había enviado los mármoles para los correspondientes sepulcros y un pilar de pórfido para el púlpito, encargando a su hermano Alonso la vigilancia de las obras hasta su regreso en 1507. La capilla fue encomendada a Antón y Enrique Egás ${ }^{144}$, mientras Alonso de Covarrubias se ocupaba del sepulcro de sus padres - dos frontales decorados al romano- al menos desde 1510, y Antonio de Comontes y Juan de Borgoña de los tres retablos destinados a la capilla mayor y los testeros del crucero (1513) ${ }^{145}$. La capilla contaba con vidrieras y una reja realizada por Juan Francés. Rojas no se preocupó solo de embellecer su capilla

\footnotetext{
139 J. Manglano y Cucalo de Montull (Barón de Terrateig) (1963), I, pp. 47, 59, 60, 63-67 y 149-156; II, pp. 17-18, 26, 29, 31, 39-40 y 50.

${ }^{140}$ T. de Azcona (1960), pp. 181, 188-189 y ss.

${ }^{141}$ J. García Oro (2009), pp. 625-720.

142 Th. Frenz (1989), p. 333 (n. 765).

${ }^{143}$ Las vicisitudes de la obra han sido estudiadas por R. Ramírez de Arellano (1921), pp. 1020; F.de B. San Román (1984), p. 215; I. Cadiñanos Bardeci (2006), p. 6.

${ }^{144}$ J.M. Azcárate (1958), pp. 30 y 39.

${ }^{145}$ F. de B. San Román (1984), pp. 215-216.
} 
concluida en 1521, sino que la dotó con indulgencias -obtendias de Alejandro VI y Julio II- para promover la oración por su familia den determinadas festividades y un capital procedente de la reserva de beneficios que tutelaba Francisco Ruiz, secretario de Cisneros.

También adquirió las casas donde estaba el Colegio de Santa Catalina, que eran lindantes con su domicilio familiar (21.VII.1520), y luego las revendió a Francisco Álvarez Zapata para la Universidad recién erigida. Según González de Oviedo, Rojas administró ejemplarmente su hacienda "para le servir con ella [a Dios], y la repartir con sus deudos", sin olvidar que "a pobres dio mucho"146.

Fernando el Católico recurrió a su antiguo servidor en febrero de 1513, solicitando su colaboración en las negociaciones para la tregua con Francia que debía poner fin al cisma del concilio de Pisa ${ }^{147}$. Desde su retiro en la villa de Layos, apoyó a Carlos I prestándole diversas cantidades para los gastos de guerra. Sus últimos años de vida se vieron ensombrecidos por el movimiento comunero que le obligó a firmar una serie de capítulos en prejuicio de "su derecho, jurisdicción y señorío" sobre la villa Layos (22.X.1520), que tiempo después Rojas impugnó ${ }^{148}$. Durante los altercados, mantuvo la fortaleza de Calatrava y en noviembre de 1521 entregó al ejército imperial cinco millones de maravedíes a cambio del privilegio de juro.

En junio de 1516 Margarita volvió a presentar su querella contra el antiguo embajador por apropiarse de ciertos dineros recibidos de la reina Católica y del archiduque con destino a ella. Aunque el proceso se resolvió favorablemente para Rojas, su extraña actitud al no querer reconocer su letra en un documento que contradecía su testimonio oral, o sus cambios de parecer a medida que se le presionaba con nuevos argumentos y datos, le convierten en sospechoso, a menos que la edad y el tiempo trascurrido mermaran su lucidez mental. Sea como fuere, su biografía pone de manifiesto una vida al servicio de la Corona, su "mucha experiencia en los negocios de estado" - como apunta Zurita ${ }^{149}$, y su integridad de caballero "religioso y limosnero [...] que murió virgen y no conoció mujer ni se le oyó jamás palabra deshonesta", según G. Fernández de Oviedo ${ }^{150}$. Algunas anécdotas manifiestan su astucia para negociar, su vehemencia en la defensa de los derechos de sus soberanos, así como su sensibilidad hacia las letras italianas, los objetos suntuarios y la miniatura flamenca. Fue enterrado en la capilla de la Epifanía por él fundada, con una lápida conmemorativa de sus servicios prestados a los Reyes Católicos, recordando expresamente la "empresa e conquista del reino de Nápoles e Jerusalén".

${ }^{146}$ G. Fernández de Oviedo (2000), III, p. 273.

147 J. M. Doussinague (1946), p. 588.

${ }^{148}$ P. López Pita (1986), pp. 591-602; F. Martínez Gil (1993), ad indicem.

${ }^{149}$ J. Zurita (1996), vol. II, libro III, cap. XXXVIII, p. 295.

${ }^{150}$ G. Fernández de Oviedo (2000), III, p. 273. 


\section{Obras citadas}

Agapito Y Revilla, Juan: Los retablos de Medina del Campo, Valladolid, Tipografía del Colegio Santiago, 1916.

Alcocer Martínez, Mariano (ed.): Historia de la Universidad de Valladolid: expedientes de provisiones de cátedras, ordenados y anotados por Mariano Alcocer Martinez, Valladolid, Imprenta Castellana, 1921.

Álvarez PAlENZUEla, Vicente Ángel: "Los intereses aragoneses en Italia: presiones de Alfonso V sobre el pontificado", en XIV Congresso di storia della Corona d'Aragona, vol. III, Sassari, 1996, pp. 65-89.

ANDRÉS DÍAZ, Rosana de: El último decenio del reinado de Isabel I a través de la tesorería de Alonso de Morales (1495-1504), Valladolid, Universidad de Valladolid, 2004.

ANDRÉS MARTíN, Melquíades: La teología española en el siglo XVI, vol. I, Madrid, Biblioteca de Autores Cristianos, 1976.

ANgeli, Sebastiano: Legenda volgare di Colomba da Rieti, ed. G. Casagrande, Espoleto, Centro Italiano di Studi sull'Alto Medioevo, 2002.

AuriA, Vincenzo: Del' origine et antichita di Cefalu citta di Sicilia, Palermo, Cirilli, 1656.

AZCÁRATE, José María de: Arquitectura gótica toledana del siglo XV, Madrid, Instituto Diego Velázquez, 1958.

AZCONA, Tarsicio de: La elección y reforma del episcopado español en tiempos de los Reyes Católicos, Madrid, Consejo Superior de Investigaciones Científicas, 1960

-----: "Relaciones de Inocencio VIII con los Reyes Católicos, según el fondo Podocataro de Venecia", Hispania Sacra, 32 (1980), pp. 3-30.

-----: Isabel la Católica. Estudio crítico de su vida y reinado, Madrid, Biblioteca de Autores Cristianos, 1993.

BACKHOUSE, Janet: The Isabella Breviary, Londres, The Bristish Library, 1993.

Balenchana, José Antonio de (ed.), Cancionero General, Madrid, Sociedad de Bibliófilos, 1882.

BASelga y RAmíreZ, Mariano (ed.): Cancionero catalán de la Universidad de Zaragoza, Zaragoza, Cecilio Gasca, 1896.

BECEIRO PITA, Isabel: "La importancia de la cultura en las relaciones peninsulares (siglo XV)", Anuario de Estudios Medievales, 29 (1999), pp. 79-104.

BeltrÁn de Heredia, Vicente: Cartulario de la Universidad de Salamanca, vol. II-V, Salamanca, Universidad de Salamanca, 1970-1972.

BERnÁldeZ, Andrés: Memorias del reinado de los Reyes Católicos, ed. de M. Gómez-Moreno y Juan de M. Carriazo, Madrid, Patronato Marcelino Menéndez Pelayo, 1962.

Bertola, Maria: I due primi registri di prestito della Biblioteca apostolica vaticana, codici vaticani latini. 3964, 3966, Ciudad del Vaticano, Biblioteca Apostólica Vaticana, 1942. 
Blanco Contano, Mateo: "La Catedral de Badajoz, cuna de la educación pacense", en F. Tejada Vizuete (dir.), La Catedral de Badajoz, 1255-2005, Badajoz, Tecnigraf, 2007, pp. 207-230.

Bofarull, Manuel de: "Opúsculos inéditos del cronista catalán Pere Miquel Carbonell", en Colección de documentos inéditos del Archivo General de la Corona de Aragón, vol. 28, Barcelona, 1865, pp. 369-374.

BURCKARDT, Johann: Liber notarum ab anno 1483 usque ad annum 1506, ed. E. Celani, vol. I-II, Città di Castello, Editrice S. Lapi, 1907-1942.

BURCKHARDT, Jacob, La cultura del Renacimiento en Italia, Madrid, Akal, 2004.

CADIÑANOS BARDECI, Inocencio: "Precisiones acerca del Tránsito de la Virgen de Juan Correa de Vivar", Boletín del Museo del Prado, 24-42 (2006), pp. 613.

CALMETTE, Joseph: Louis XI, Jean II et la révolution catalane (1461-1473), Ginebra, Slatkine, 1902 (ed. 1977).

Cançoner del marquès de Barberà, Biblioteca del Monasterio de Montserrat, ms. 992.

CAntatore, Flavia: San Pietro in Montorio: la chiesa dei Re Cattolici a Roma, Roma, Quasar, 2007.

Capitulos y ordenamientos de la Inquisición, Real Biblioteca (Madrid), II/2383.

CAPPELLI, Guido Maria: "Diplomacia humanista. Nápoles aragonés y Borgoña en el discurso político y literario", en J. Martínez Millán, M. Rivero Rodríguez (coord.): Centros de poder italianos en la monarquía hispánica (siglos XV-XVIII), vol. 2, Polifemo, Madrid, 2010, pp. 1147-1166.

CARANDE, Ramón y Juan de Mata CARRIAZO (eds.): El Tumbo de los Reyes Católicos del Concejo de Sevilla, vol III: Años 1479-1485, Sevilla, Editorial Católica Española, 1968.

Castellanos De LosadA, Basilio Sebastián (dir.): Biografía eclesiástica, vol. XXIV, Madrid, Imprenta de Alejandro Gómez Fuentenebro, 1863.

CENCI, Caesar. (ed.): Bullarium Franciscanum: continens bullas brevia supplicationes tempore Romani Pontificis Innocentii VIII pro tribus ordinibus S.P.N. Francisci obtenta, Grottaferrata, Collegii S. Bonaventurae ad Claras Aquas, 1989.

Civitates: ciudades y comercio en la Europa de los siglos XVI y XVII, Diputación de Valladolid, Medina del Campo, Fundación Museo de las Ferias, 2010.

CLARK, Gregory T.: The hours of Isabel la Católica, Madrid, Patrimonio NacionalTestimonio Compañía Editorial-Münster-Bibliotheca Rara, 1997.

ColmenARES, Diego. de: Historia de la insigne ciudad de Segovia y compendio de las historias de Castilla, vols. I-II, Segovia, Academia de Historia y Arte de San Quirce, 1969.

CROCE, Benedetto, España en la vida italiana del Renacimiento, Madrid, Editorial Renacimiento, 2007 ( $1^{\text {a }}$ ed. 1949), 
DE GRASSIS, Paris: Le due spedizioni militari di Giulio II tratte dal Diario di Paride de Grassi bolognese, ed. de L. Frati, Bolonia, 1886.

DíaZ Cassou, Pedro: Serie de los Obispos de Cartagena. Sus hechos y su tiempo, Madrid, 1895.

Doussinague, José María: La política internacional de Fernando el Católico, Madrid, Espasa-Calpe, 1944.

-----: Fernando el Católico y el cisma de Pisa, Madrid, Espasa Calpe, 1946.

DUQue DE BERWICK Y DE AlBA: Correspondencia de Gutierre Gómez de Fuensalida, embajador en Alemania, Flandes e Inglaterra (1496-1509), Madrid, s.n., 1907.

ENZENSBERGER, Horst: "I vescovi francescani in Sicilia (sec. XIII-XV)", en Francescanesimo e cultura in Sicilia (secc. XIII-XVI), Palermo, Officina di Studi Medievali, 1987, pp. 45-62.

EuBEL, Conrad: Hierarchia Catholica Medii Aevi, vol. II, Patavii, Il Messaggero di S. Antonio, 1898-1923.

FARENGA, Paola: "Ciscostanze e modi della diffusione dell' "Historia Baetica", en M. Chiabò, P. Farenga y M. Miglio (dirs.): Caroli Verardi. Historia Baetica. La Caduta di Granata nel 1492, Roma, Bibliotheca scriptorum LatinorumRR inedita, 1993, pp. XV-XXXV.

FERNÁNDEZ DE CóRDOVA MIRALlES, Álvaro: "Sociedad cortesana y entorno regio”, en, Miguel Ángel Ladero Quesada (dir.): El mundo social de Isabel la Católica. La sociedad castellana a finales del siglo XV, Madrid, Dykinson, 2004, pp. 49-78.

-----: Alejandro VI y los Reyes Católicos. Relaciones político-eclesiásticas (14921503), Roma, Edizioni Università della Santa Croce, 2005.

-----: "Reyes Católicos: mutaciones y permanencias de un paradigma político en la Roma del Renacimiento", en C. J. Hernando Sánchez (coord.): Roma y España. Un crisol de la cultura europea en la Edad Moderna, Madrid, Sociedad Estatal para la Acción Cultural Exterior, 2007 a, pp. 133-154.

-----: "Alejandro VI y los Reyes Católicos. Afinidades y diferencias al final de un pontificado (1498-1503)", en La llum de les imatges (abril-diciembre 2007), Valencia, Generalitat Valenciana, 2007 b, pp. 281-299.

-----: "López de Carvajal, Bernardino", en Diccionario Biográfico Español, vol. 30, Madrid, Real Academis de la Historia, 2009, pp. 395-401.

-----: "Cèsar Borja en el seu context històric: entre el pontificat i la monarquia hispànica”, en Á. Fernández de Córdova Miralles, J. Arrizabalaga, y M. Toldrà: Cèsar Borja cinc-cents anys després (1507-2007). Tres estudis $i$ una antologia, Valencia, 2009, pp. 11-98.

-----: “Ruiz de Medina, Juan”, en Diccionario Biográfico Español, vol. 44, Madrid, Real Academia de la Historia, 2013 a, pp. 784-786.

-----: "Vidal de Noya, Francisco", en Diccionario Biográfico Español, vol. 49, Madrid, Real Academia de la Historia, 2013 b, pp. 902-904. 
-----: "Fernando el Católico y Julio II: Papado y Monarquía hispánica a comienzos de la modernidad" (en preparación).

-----: "Los Reyes Católicos ante la elección pontificia de Pío III: la acción negociadora hispana en sede vacante (1503)", en Pere Miquel Carbonell $i$ el seu temps (1434 - 1517), Reial Acadèmia de Bones Lletres de Barcelona (en prensa).

----- y Concepción VILLANUEVA MORTE: "Juan Claver, embajador de los Reyes Católicos en la Italia del Renacimiento" (en preparación).

----- y V. CALVO FERNÁNDEZ: "La muerte del heredero. Liturgia y humanismo por el príncipe Juan en su marco europeo" (en preparación).

FERNÁNDEZ DE OvIEDO, Gonzalo: Batallas y quinquágenas, ed. J. Pérez de Tudela y Bueso, vol. III, Madrid, 2000.

FitA, Fidel: Los Reys d'Aragó y la Seu de Girona des de l'any 1462 fins al 1482. Collecció d'actes capitulars, Barcelona, Estampa catalana de L. Obradors y P. Sulé, 1873.

-----: "Cartas inéditas de D. Arnaldo Descós", Boletín de la Real Academia de la Historia, 19 (1891), pp. 377-446.

-----: "Primeros años del episcopado de América", Boletín de la Real Academia de la Historia, 20 (1892), pp. 263-272.

Floreto de anécdotas y noticias diversas que recopiló un fraile dominico residente en Sevilla a mediados del siglo XVI, ed. F. J. Sánchez Cantón, Memorial histórico español, vol. 48, Madrid, Imprenta de la Real Academia de la Historia, 1948.

FlóREZ, Enrique.: España Sagrada, vol. XVI: La Iglesia de Astorga, Madrid, Editorial Revista Agustiniana, 2005.

Fragnito, Gigliola: "Carvajal, Bernardino López de", en Dizionario Biografico degli Italiani, vol. 21, Roma, Treccani, 1978, pp. 28-34.

Frigo, Daniella (ed.): Politics and Diplomacy in Early Modern Italy. The Structure Diplomatic Practice, 1450-1800, Cambridge, Cambridge University Press, 2000.

FrenZ, Thomas: Die Kanzlei der Papste der Hochrenaissance (1471-1527), Roma, Niemeyer, 1989.

FRÜH, Martin: "Antonio Geraldini en el mundo catalano-aragonés de su época: resultados de una tesis doctoral", en I Geraldini di Amelia nell'Europa del Rinascimento. Atti del Convegno Storico Internazionale, Amelia 21-22 novembre 2003, Terni-Amelia, 2004, pp. 65-69.

GAMERO ROJAS, Mercedes: "Istruzioni spagnole", en A. PROSPERI (dir.), Dizionario storico dell'Inquisizione, vol. II, Pisa, Edizione della Normale, 2010.

GARCÍA Y GARCÍA, Antonio: "Nuevos descubrimientos sobre la canonística salmantina del siglo XV", Anuario de historia del derecho español, 50 (1980), pp. 361-374. 
García ORO, José: El Cardenal Cisneros: vida y empresas, vol. I, Madrid, Biblioteca de Autores Cristianos, 1992.

-----: "Francisco de Rojas (1446-1523): apuntes biográficos sobre un diplomático toledano cercano al Cardenal Cisneros", Archivo ibero-americano, 69/264 (2009), pp. 625-720.

GARrigA, Carlos: La Audiencia y las Chancillerias castellanas (1371-1525). Historia política, régimen jurídico y práctica institucional, Madrid, Centro de Estudios Constitucionales, 1994.

GIL, Juan: Los conversos y la Inquisición sevillana, vol. I, Sevilla, Universidad de Sevilla-Fundación El Monte, 2000.

GiURATo, Simona: La Sicilia di Ferdinando il Cattolico. Tradizioni politiche e conflitto tra Quattrocento e Cinquecento (1468-1523), Mesina, Rubbettino, 2003.

GiUstinian, Antonio: Dispacci, ed. P. Villari, vols. I-III, Florencia, Le Monnier, 1876.

Gómez Menor, C.: "Los Rojas de Toledo", Anales Toledanos, 6 (1963), pp. 183197.

Gómez Moreno, Ángel: España y la Italia de los humanistas. Primeros ecos, Madrid, Gredos, 1994.

-----: “Del Duecento al Quattrocento: Italia en España, España en Italia”, Ínsula, 757-758 (2010), pp. 7-11.

GONZÁLEZ ARÉVALO, Raúl: "Ecos de la toma de Granada en Italia: de nuevo sobre las cartas a Milán y Luca", en Homenaje al profesor Eloy Benito Ruano, vol. I, Murcia, 2010, pp. 343-353.

GONZÁlEZ RolÁN, Tomás y SAQUERO SuÁREZ-SOMONTE, Pilar: "Los comienzos de la diplomacia moderna en Castilla: Alfonso de Cartagena (13851456)", La Corónica: A Journal of Medieval Hispanic Languages, Literatures and Cultures, 39-1 (2010), pp. 147-160.

-----: HERNÁNDEZ, Fremiot y SAQUERO, Pilar: Diplomacia y humanismo en el siglo $X V$, Madrid, Universidad Nacional de Educación a Distancia, 1994.

GOÑI GAZTAMBIDE, José: "Bernardino López de Carvajal y las bulas alejandrinas", Anuario de Historia de la Iglesia, 1 (1992), pp. 93-112.

Gotor LóPEZ, José Luis: "Il carme De casu regis di Pietro Martire d'Anghiera e la tragicomedia Fernandus seruatus di Marcellino Verardi", en su Carte spagnole. Dieci saggi di letture e ricerche, Perusa, 1984, pp. 1-25.

Historia del pontificado de Alejandro VI hasta 1501, Gerona, Biblioteca del Seminario Diocesano, ms. 12.

IANUZZI, Isabella: "Bernardino de Carvajal: teoria epropaganda di uno spagnoloall' interno della curia romana", Rivista di Storia della Chiesa in Italia, 62 (2008), pp. 24-45. 
LATASSA Y ORTín, Félix de.: Bibliotheca antigua de los escritores aragoneses, vol. II, ed. G. Lamarca Langa, Real Sociedad Económica Aragonesa, Zaragoza, 2004.

LEA, Henry Charles de: Historia de la Inquisición española, vol. I, Madrid, Fundación Universitaria Española, 1983.

LECEA, Carlos de: "Memorial histórico de Segovia, escrito por don Juan de Pantigoso en 1523", Boletín de la Real Academia de la Historia, 14 (1889), pp. 214-261.

LÓPEz PITA, Paulina: "Las Comunidades frente a Francisco de Rojas", En la España Medieval, 9 (1986), pp. 591-602.

-----: "Francisco de Rojas: embajador de los Reyes Católicos", Cuadernos de Investigación Histórica, 15 (1994), pp. 99-149.

MADRID SOUTO, Raquel: "Francisco Vidal de Noya, embajador del Rey Católico", en M. González Jiménez y I. Montes Romero-Camacho (eds.): La Península Ibérica entre el Mediterráneo y el Atlántico. Siglos XIII-XV, Sevilla-Cádiz, Diputación de Cádiz-Sociedad Española de Estudios Medievales, 2006, pp. 449-456.

Manglano y Cucalo De Montull, Joaquín (Barón de Terrateig): Política en Italia del Rey Católico (1507-1516). Correspondencia inédita con el embajador Vich, vol. I-II, Madrid, Consejo Superior de Investigaciones Científicas, 1963.

MARQUÉS CASASNOVAS, Jaime: "Fernando el Católico y la catedral de Gerona", Revista de historia Jerónimo Zurita, 14-15 (1963), pp. 55-75.

MARTí, Sadurní: "El Cançoner del marquès de Barberà $\left(S^{l} / B M 1\right)$. Descripció codicològica (1)", en Boletín Bibliográfico de la Asociación Hispánica de Literatura Medieval, 11 (1997), pp. 463-502.

MARTÍN GARCÍA, Juan Manuel: Arte y diplomacia en reinado de los Reyes Católicos, Madrid, Fundación Universitaria Española, 2003.

-----: "La diplomacia en la Edad Moderna: perspectivas para una construcción de la identidad cultural de Europa”, en J. J. Ferrer Maestro, y P. Barceló (coord.): Europa: historia, imagen y mito. V Coloquio del Grupo Europeo de Investigación histórica "potestas", Barcelona, Universitat Jaume I, 2008, pp. 487-500.

-----: "Rojas y Escobar, Francisco de", en Diccionario Biográfico Español, vol. 44, Real Academia de la Historia, Madrid, 2013, pp. 230-232.

MARTín POSTIGO, María de la Soterraña: Los presidentes de la Real Chancillería de Valladolid, Valladolid, Institución Cultural Simancas, 1982.

MARTíNeZ GIL, Fernando: La ciudad inquieta. Toledo comunera, 1520-1522, Toledo, Instituto Provincial de Investigaciones y Estudios Toledanos, 1993.

Mattingly, Garret: La Diplomacia del Renacimiento, Madrid, Instituto de Estudios Políticos, 1970. 
Miglio, Massimo: "Continuità e fratture nei rapporti tra Papato e Spagna nel Quattrocento", en En los umbrales de España: la incorporación del Reino de Navarra a la monarquía hispana (XXXVIII Semana de estudios medievales, Estella, 18-22 de julio de 2011), Pamplona, 2012, pp. 279296.

MisuraCA, Giuseppe: Serie dei Vescovi di Cefalù, Roma, S. Nilo, 1960.

MONFASANI, John: Fernando of Cordova: a biographical and intellectual profile, Philadelphia, American Philosophical Society, 1992.

Moraleja Pinilla, Gerardo: Historia de Medina del Campo, Medina, Manuel Mateo, 1971.

NAVARro Sorní, Miguel: Calixto III Borja y Alfonso el Magnánimo frente a la cruzada, Ayuntamiento de Valencia, Valencia, 2003.

NIETO SORIA, José Manuel: "La dimensión cultural de la diplomacia castellanoleonesa en la época Trastámara", en M. C. Cosmen Alonso, M. V. Herráez Ortega, y M. Pellón Gómez-Calcerrada (coord.), El intercambio artístico entre los reinos hispanos y las cortes europeas en la Baja Edad Media, León, Universidad de León, 2009, pp. 15-28.

OCHOA BRUN, Miguel Ángel: "La Diplomacia española y el Renacimiento", Cuadernos de la Fundación Pastor (1989), pp. 27-63.

-----: Historia de la Diplomacia Española, vol. IV, Madrid, Ministerio de Asuntos Exteriores, 1995.

-----: Miscelánea diplomática, Madrid, Real Academia de la Historia, 2012.

OlIVA, Anna Maria: "La diplomazia dei Re Cattolici presso la Curia romana", en B. Anatra, y G. Murgia (dir.), Sardegna, Spagna e Mediterraneo. Dai Re Cattolici al secolo d'oro, Roma, Carocci, 2004, pp. 57-68.

OliVARES TEROL, María José: "Los obispos de la diócesis cartaginense durante el siglo XVI y sus relaciones con el cabildo catedralicio", Murgetana, 109 (2003), pp. 47-65.

ORTIZ DE ZÚÑIGA, Diego: Anales eclesiásticos y seculares de la muy noble y muy leal ciudad de Sevilla, vol. I, Madrid, Imprenta Real, 1795.

PABÓN, José María: "Las primeras traducciones españolas de Salustio", Emerita, 20 (1952), pp. 412-422.

Palencia, Alonso de: Crónica de Enrique IV, ed. de A. Paz y Meliá, vol. II, Madrid, Ediciones Atlas, 1975.

-----: Guerra de Granada, estudio preliminar de R. G. Peinado Santaella, Granada, Universidad de Granada, 1998.

PELLEGRINI, Marco: Il papato nel Rinascimento, Bolonia, Il mulino, 2010.

Perea RodríGUeZ, Óscar: "Vidal de Noya, Francisco (ca. 1415-1492)" en http://www.mcnbiografias.com/app-bio/do/show?key=vidal-de-noyafrancisco.

----- y MADRID SOUTO, R.: "Francisco Vidal de Noya, obispo de Cefalú: clérigo, humanista y poeta al servicio del rey Católico", en XVII Congreso de 
Historia de la Corona de Aragón, vol. II, Barcelona-Lérida, Publicacions Universitat de Barcelona, 2003, pp. 745-767.

PIRRI, Rocco: Sicilia Sacra. Disquisitionibus et notitiis illustrata, Vol. II Palermo, Arnal de Forni, 1753.

QUARANTA, Giovanni: 'L' intricata vicenda delle origini di Monsignor Francesco Vitali”, Calabria Sconosciuta 28-105 (2005), pp. 53-55.

RAMíREZ DE ARELlANO, Rafael: Las parroquias de Toledo, Toledo, 1921.

RinCÓN GONZÁlEZ, María Dolores: "La divulgación de la Toma de Granada: objetivos, mecanismos y agentes", Anuario de estudios medievales, 40-2 (2010), pp. 603-615.

RODRíGUeZ VILlA, Antonio: La reina doña Juana la Loca, estudio histórico, Madrid, Libreria de M. Murillo, 1892.

-----: "Don Francisco de Rojas, embajador de los Reyes Católicos", Boletín de la Real Academia de la Historia, 28 (1896), pp. 180-202, 295-339, 364-402 y 440-474; 29 (1896), pp. 5-69.

RoJas, Pedro de: Discursos ilustres, históricos y genealógicos, por D. Pedro de Rojas, caballero de la Orden de Calatrava, Conde de Mora, señor de la Villa de Laios y el Castañar, Toledo, Juan Ruiz de Pereda (impresor), 1636.

RouZIÈs, Étienne: Lectures médiévales de Salluste, Thèses de l'Ecole nationale des Chartes, París, 2004.

Rovira, José Carlos: Humanistas y poetas en la corte napolitana de Alfonso el Magnánimo, Alicante, Instituto de Cultura Juan Gil-Albert, 1990.

RUBió I BALAGUER, Jordi: "Sobre Sallusti a la cancelleria catalana", Spanische Forschungen del Görresgesellshaft, 21 (1963), pp. 233-249

RUIZ GARCÍA, Elisa: "Los breviarios de la reina católica: un signo de modernidad", en III Jornadas científicas sobre Documentaciónen época de los Reyes Católicos, Madrid, Departamento de CC. Y TT. Historiográficas, 2004, pp. 221-248.

SALVADOR Miguel, Nicasio: "Intelectuales españoles en Roma durante el gobierno de los Reyes Católicos", en Rumbos del hispanismo en el umbral del Cincuentenario de la AIH, vol. I, Roma, Bagatto Libri, 2012, pp. 47-64.

SÁnchez del BARrio, Antonio: Fundación Museo de las Ferias. "La pieza del mes" 2000-2010, Valladolid, Diputación de Valladolid y Fundación Museo de las Ferias, 2011.

SANUdo, Marino: Diarii, vols. II-XIV, ed. R. Fulin, Venecia, 1879-1903.

SAN ROMÁn, Francisco de Borja: "La parroquia de San Andrés. Notas históricas", Toletum: Boletín de la Real Academia de Bellas Artes y Ciencias Históricas de Toledo, 15 (1984), pp. 207-219.

SERIO, Alessandro: "Una representación de la crisis de la unión dinástica: los cargos diplomáticos en Roma de Francisco de Rojas y Antonio de Acuña (1501-1507)”, en Isabel la Católica y su época (Actas del Congreso 
Internacional, Valladolid-Barcelona-Granada, 2004), Valladolid, Instituto Universitario de Historia Simancas, 2007, pp. 849-862.

SERRANO Y PINEDA, Luciano Ildefonso (ed.), "Correspondencia de los Reyes Católicos con el Gran Capitán durante las campañas de Italia", Revista de Archivos Bibliotecas y Museos, 21 (1909), pp. 441-359 (serie de artículos hasta) 29 (1912), pp. 300-312.

-----: "Noticias inéditas del Gran Capitán”, Boletín de la Real Academia de la Historia, 79 (1921), pp. 225-275.

-----: "Nuevos datos sobre el Gran Capitán", Hispania, 3 (1943), pp. 70-88.

SETTANNI, Giacomo: Toponomastica nojana. Strade, piazze e contrade. 1824-1954, Fasano, Schena, 2001.

SHAw, Christine: "The papal court as a centre of diplomacy: from the peace of Lodi to the Council of Trent", en F. La Brasca (dir.), La papauté à la Renaissance, Paris, Alazard, 2007, pp. 621-638.

SORIA, Andrés: Los humanistas de la Corte de Alfonso el Magnanimo (según los epistolarios), Granada, Universidad de Granada, 1956.

SPARACIO, Domenico: Siciliensis provinciae Ordinis minorum conventualium conspectus historicus. Addita notitia neo-provinciae melitensis eiusdem ordinis, Roma, Typis polyglottis vaticanis, 1925.

SuÁREZ FERNÁNDEZ, Luis: Politica internacional de Isabel la Católica. Estudio y documentos, vol. I-VI, Valladolid, Universidad de Valladolid, 1965-2002.

----- y CARriazo ARroquia, Juan de Mata: La España de los Reyes Católicos (1474-1515), Historia de España Menéndez Pidal, t. XVII, vols. I-II, Madrid, Espasa Calpe, 1969.

TATE, Robert Brian: Ensayos sobre la historiografía peninsular del siglo $X V$, Madrid, Gredos, 1970.

TORRE Y DEL CERRO, Antonio de la: Documentos sobre las relaciones internacionales de los Reyes Católicos, vol. I-V, Barcelona, Consejo Superior de Investigaciones Científicas, 1949-1966.

TORRES FONTES, Juan: Estampas de la vida murciana en la época de los Reyes Católicos, Murcia, Academia Alfonso X El Sabio, 1984.

UstÁrROZ, Juan Francisco Andrés de: Biblioteca de los escritores del reino de Aragón, Biblioteca Nacional de España (Madrid), Ms. 9793.

VARONA GARCíA, María Antonia: La Chancillería de Valladolid en el reinado de los Reyes Católicos, Valladolid, Universidad de Valladolid, 1981

VegA, Garcilaso de la (ed.), Carta a los Reyes Don Fernando y Doña Isabel de su embajador en Roma en 1498, San Sebastián, Imprenta de Ignacio Ramón Baroja, 1842.

VICENS VIVES, Jaume: Historia crítica de la vida y reinado de Fernando II de Aragón, Zaragoza, Institución Fernando el Católico, 1962. 
Vilallonga, M.: La literatura llatina a Catalunya al segle XV. Repertori biobibliogràfic, Barcelona, Curial: Publicacions de l'Abadia de Montserrat, 1993.

Villarroel GonzÁlez, Óscar: El Rey y el Papa: política y diplomacia en los albores del Renacimiento, Madrid, Silex, 2010.

VILlASEÑOR SEBASTIÁN, Fernando: "Juan Ruíz de Medina, regio oratori in romana curia, y un conjunto de sus incunables miniados", en M. C. Cosmen Alonso, M. V. Herráez Ortega, y M. Pellón Gómez-Calcerrada (coord.): El intercambio artístico entre los reinos hispanos y las cortes europeas en la Baja Edad Media, León, Universidad de León, 2009, pp. 239-252.

VISCEGLIA, Maria Antonietta, Roma papale e Spagna: diplomatici, nobili e religiosi tra due corti, Roma, Bulzoni, 2010.

VOLPI, Giovanni (ed.): La resa di Granata (1492) descritta dall'orator di Castiglia e di Aragona presso la S. Sede dalle carte dell'Archivio di Stato di Lucca, Luca, 1889.

WADDING, Lucas: Annales Minorum seu Trium Ordinum a S. Francisco institutorum, vol. XIV: 1472-1491, Florencia, Tipografía Barbèra, 19311964

WoODWARD, William Harrison: Cèsar Borja, prólogo de J. Benavent y revisión de M. Toldrà Valencia, Tres i Quatre, 2005.

YARZA LUACES, Joaquín: Los Reyes Católicos: paisaje artístico de una monarquía, Madrid, Nerea, 1993.

-----: La nobleza ante el rey: los grandes linajes castellanos y el arte en el siglo XV, Madrid, El Viso, 2004.

ZURITA, Jerónimo: Historia del rey don Hernando el Cathólico. De las empresas y ligas de Italia, ed. A. Canellas López, vol. II-III, Zaragoza, Gobierno de Aragón, 1996. 


\section{APÉNDICE}

\section{FUENTES Y BIBLIOGRAFÍA}

\section{Diplomacia y literatura para una nueva monarquía}

Bibliografía: F. García Olmedo, Humanismo y diplomacia bajo los Reyes Católicos, Madrid, Escuela Diplomática, 1949; A. SORIA, Los humanistas de la Corte de Alfonso el Magnanimo (según los epistolarios), Universidad de Granada, Granada, 1956; G. Mattingly, La Diplomacia del Renacimiento, Madrid, Instituto de Estudios Políticos, 1970; R. B. TATE, Ensayos sobre la historiografia peninsular del siglo XV, Madrid, Gredos, 1970; M. Á. OCHOA BRUN, "La Diplomacia española y el Renacimiento", en Cuadernos de la Fundación Pastor, 1989 (1989), pp. 27-63; ID., Historia de la Diplomacia Española, vol. IV, Madrid, Ministerio de Asuntos Exteriores, 1995; ID., Miscelánea diplomática, Real Academia de la Historia, Madrid, 2012; J. C. RovirA, Humanistas y poetas en la corte napolitana de Alfonso el Magnánimo, Alicante, Instituto de Cultura Juan Gil-Albert, 1990; Á. Gómez Moreno, España y la Italia de los humanistas. Primeros ecos, Madrid, Gredos, 1994; ID., "Del Duecento al Quattrocento: Italia en España, España en Italia", en Ínsula, 757-758 (2010), pp. 7-11; T. GonzÁlez Rolán, F. Hernández, y P. SAQuero, Diplomacia y humanismo en el siglo XV, Madrid 1994; T. GonZÁleZ Rolán, F. HERNÁNDEZ, y P. SAQUERO, "Los comienzos de la diplomacia moderna en castilla: Alfonso de Cartagena (1385-1456)", La corónica: A Journal of Medieval Hispanic Languages, Literatures \&Cultures, 39-1(2010), pp. 147-160; V. Á. Álvarez PAlENZUELA, "Los intereses aragoneses en Italia: presiones de Alfonso V sobre el pontificado", en XIV Congresso di storia della Corona d'Aragona, vol. III, Sassari, 1996, pp. 65-89; I. BECEIRO PITA, "La importancia de la cultura en las relaciones peninsulares (siglo XV)", en Anuario de Estudios Medievales, 29 (1999), pp. 79-104; D. FrIGO (ed.), Politics and Diplomacy in Early Modern Italy. The Structure Diplomatic Practice, 1450-1800, Cambridge, Cambridge University Press, 2000; M. NAVARRo SORNí, Calixto III Borja y Alfonso el Magnánimo frente a la cruzada, Ayuntamiento de Valencia, Valencia, 2003; J. M. MARTín GARCÍA, Arte y diplomacia en reinado de los Reyes Católicos, Madrid, Fundación Universitaria Española, 2003; ID., "La diplomacia en la Edad Moderna: perspectivas para una construcción de la identidad cultural de Europa", en J. J. FERRER MAESTRO, y BARCEló, P. (coord.), Europa: historia, imagen y mito. $V$ Coloquio del Grupo Europeo de Investigación histórica "potestas", Universitat Jaume I, 2008, pp. 487-500; A. M. OlIVA, "La diplomazia dei Re Cattolici presso la Curia romana", en B. AnATRA, y G. Murgia (dir.), Sardegna, Spagna e Mediterraneo. Dai Re Cattolici al secolo d'oro, Carocci, Roma, 2004, pp. 57-68; Á. FERNÁNDEZ DE CóRDOVA MIRALlES, "Sociedad cortesana y entorno regio", en M. Á. LADERO QUESADA (dir.), El mundo social de Isabel la Católica. La sociedad castellana a finales del siglo XV, Madrid, Dykinson, 2004, pp. 49-78; ID., Alejandro VI y los Reyes Católicos. Relaciones político-eclesiásticas (1492-1503), Roma, 2005; ID., "Reyes Católicos: mutaciones y permanencias de un paradigma político en la Roma del Renacimiento", en C. J. HERNANDO SÁNCHEZ (coord.), Roma y España. Un crisol de la cultura europea en la Edad Moderna, Sociedad Estatal para la Acción Cultural Exterior, 
Madrid, 2007, pp. 133-154; ID., y C. Villanueva MorTe, Juan Claver, embajador de los Reyes Católicos en la Italia del Renacimiento (en preparación); Ch. SHAw, "The papal court as a centre of diplomacy: from the peace of Lodi to the Council of Trent", F. La Brasca (dir.), La papauté à la Renaissance, Alazard, Paris, 2007, pp. 621-638; J. M. NiETO SORIA, "La dimensión cultural de la diplomacia castellano-leonesa en la época Trastámara", en M. C. Cosmen Alonso, M. V. Herráez Ortega, y M. Pellón Gómez-Calcerrada (coord.), El intercambio artístico entre los reinos hispanos y las cortes europeas en la Baja Edad Media, León, Universidad de León, 2009, pp. 15-28; O. VILlarRoEL GonZÁLEZ, El Rey y el Papa: política y diplomacia en los albores del Renacimiento, Silex, Madrid, 2010; M. Pellegrini, Il papato nel Rinascimento, Bolonia, Il mulino, 2010; G. M. CAPPelli, "Diplomacia humanista. Nápoles aragonés y Borgoña en el discurso político y literario", en J. MARTínez Millán, M. Rivero RodríGuez (coord.), Centros de poder italianos en la monarquía hispánica (siglos XV-XVIII), vol. 2, Polifemo, Madrid, 2010, pp. 1147-1166; M. A. VISCEgLIA, Roma papale e Spagna: diplomatici, nobili e religiosi tra due corti, Roma, Bulzoni, 2010; N. SALVAdOR Miguel, Intelectuales españoles en Roma durante el gobierno de los Reyes Católicos, en Rumbos del hispanismo en el umbral del Cincuentenario de la AIH, vol. I, Roma, Bagatto Libri, 2012, pp. 47-64; M. MigLIO, "Continuità e fratture nei rapporti tra Papato e Spagna nel Quattrocento", en En los umbrales de España: la incorporación del Reino de Navarra a la monarquía hispana (XXXVIII Semana de estudios medievales, Estella, 18-22 de julio de 2011), Pamplona, 2012, pp. 279-296.

\section{Francesco Vitale di Noya}

OBRAS: La guerra de Yugurta y Catilinarias, Zaragoza, Pablo Hurus, 1493; Postillae ad Scoti mariani doctoris libros (atrib.); Sermones (atrib.); Gramática latina (atrib.); J. A. DE Balenchana (ed.), Cancionero General, Madrid, Sociedad de Bibliófilos, 1882, pp. 708709 y 717-718; M. BASELGA Y RAMíREZ (ed.), Cancionero catalán de la Universidad de Zaragoza, Zaragoza, Cecilio Gasca, 1896, pp. 247-256; Cançoner del marquès de Barberà, Biblioteca del Monasterio de Montserrat, ms. 992, fol. 101r.

Fuentes: Biblioteca de la Real Academia de la Historia (Madrid), Colección Salazar; Biblioteca Nacional de España (Madrid), Manuscritos.

BibliografíA: Juan Francisco Andrés de UstÁRroz, Biblioteca de los escritores del reino de Aragón, Biblioteca Nacional de España (Madrid), Ms. 9793, ff. 256r-269r; V. AURIA, Del'origine et antichita di Cefalu citta di Sicilia, Palermo, Cirilli, 1656, p. 76; R. PIRRI, Sicilia Sacra. Disquisitionibus et notitiis illustrata, vol. II, Palermo, Arnaldo Forni Editore, 1753, pp. 813 y ss; M. BofARUll, "Opúsculos inéditos del cronista catalán Pere Miquel Carbonell”, en Colección de documentos inéditos del Archivo General de la Corona de Aragón, vol. 28, Barcelona, 1865, p. 103; F. FITA, Los Reys d'Aragó y la Seu de Girona des de l'any 1462 fins al 1482. Collecció d'actes capitulars, Barcelona, Estampa catalana de L. Obradors y P. Sulé, 1873, pp. 50-51; ID., "Cartas inéditas de D. Arnaldo Descós", en Boletín de la Real Academia de la Historia, 19 (1891), pp. 387-389; F. LATASSA Y ORTín, 
Bibliotheca antigua de los escritores aragoneses, vol. II, ed. G. Lamarca Langa, Real Sociedad Económica Aragonesa, Zaragoza, 2004, pp. 374-376; J. CALMETTE, Louis XI, Jean II et la révolution catalane (1461-1473), Ginebra, Slatkine, 1902 (ed. 1977), pp. 346 y 561562; D. M. SpARACIO, Siciliensis provinciae Ordinis minorum conventualium conspectus historicus. Addita notitia neo-provinciae melitensis eiusdem ordinis, Roma, Typis polyglottis vaticanis, 1925, p. 84 (n. XXXI); CROCE, B., España en la vida italiana del Renacimiento, Madrid, Editorial Renacimiento, 2007 (1 ${ }^{\mathrm{a}}$ ed. 1949), pp. 106-107; J. M M $^{\mathrm{a}}$. PABÓN, "Las primeras traducciones españolas de Salustio", en Emerita, 20 (1952), pp. $412-$ 422; A. DE LA TORRE Y DEL CERRO, Documentos sobre las relaciones internacionales de los Reyes Católicos, vol. I, Barcelona, Consejo Superior de Investigaciones Científicas, 1949, pp. 158, 269-270, 308-311, 336-337, 342, 344-346, 379-383; vol. II, 1950, pp. 29-31, 49-51, 81-83, 125-126 y 217-218; T. DE AZCONA, La elección y reforma del episcopado español en tiempos de los Reyes Católicos, Madrid, Consejo Superior de Investigaciones Científicas, 1960, pp. 92, 140 y 143-144; ID., Isabel la Católica. Estudio crítico de su vida y reinado, Madrid, Biblioteca de Autores Cristianos, 1993, pp. 316, 433 y 562; G. MisURACA, Serie dei vescovi di Cefalù, Roma, S. Nilo, 1960, pp. 31-32; J. MARQuÉS CASASNOvas, "Fernando el Católico y la catedral de Gerona", Revista de historia Jerónimo Zurita, 14-15 (1963), pp. 63-64; L. WAdDIng, Annales Minorum seu Trium Ordinum a S. Francisco institutorum, vol. XIV: 1472-1491, Florencia, Tipografía Barbèra, 1931-1964, p. 446; J. RUBió I BALAGUER, "Sobre Sallusti a la cancelleria catalana", en Spanische Forschungen del Görresgesellshaft, 21 (1963), pp. 233-249; L. SuÁreZ FERnÁndeZ, Política internacional de Isabel la Católica. Estudio y documentos, vol. II, Valladolid, Universidad de Valladolid, 1966, pp. 25-33; 35-45 y 47; A. DE PALENCIA, Crónica de Enrique IV, ed. de A. Paz y Meliá, vol. II, Madrid, Ediciones Atlas, 1975, pp. 123-124; M. ANDRÉS MARTín, La teología española en el siglo XVI, vol. I, Madrid, Biblioteca de Autores Cristianos, 1976, p. 277; H. ENZENSBERGER, "I vescovi francescani in Sicilia (sec. XIII-XV)", en Francescanesimo e cultura in Sicilia (secc. XIII-XVI), Palermo, Officina di Studi Medievali, 1987, pp. 57 y 204; C. CENCI (ed.), Bullarium Franciscanum: continens bullas brevia supplicationes tempore Romani Pontificis Innocentii VIII pro tribus ordinibus S.P.N. Francisci obtenta, Grottaferrata, Collegii S. Bonaventurae ad Claras Aquas, 1989, p. 155; P. O. KRISTELLER, Iter Italicum, vol. IV (Alia itinera, II): Great Britain to Spain, Londres, The Warburg Institute, 1989, p. 97; J. MONFASANI, Fernando of Cordova: a biographical and intellectual profile, Philadelphia, American Philosophical Society, 1992, pp. 51-53; M. VILAllongA, La literatura llatina a Catalunya al segle XV. Repertori bio-bibliogràfic, Barcelona, Curial: Publicacions de l'Abadia de Montserrat, 1993, pp. 35-37; S. MARTí, "El Cançoner del marquès de Barberà $\left(S^{l} / B M 1\right)$. Descripció codicològica (1)", en Boletín Bibliográfico de la Asociación Hispánica de Literatura Medieval, 11 (1997), págs 463-502; G. SETTAnNI, Toponomastica nojana. Strade, piazze e contrade. 1824-1954, Fasano, Schena, 2001; Ó. Perea RodrígueZ, "Vidal de Noya, Francisco (ca. 1415-1492)" en http://www.mcnbiografias.com/app-bio/do/show?key=vidal-de-noya-francisco; ID., y R. MADRID SoUTO, "Francisco Vidal de Noya, obispo de Cefalú: clérigo, humanista y poeta al servicio del rey Católico", en XVII Congreso de Historia de la Corona de Aragón, vol. II, Barcelona-Lérida, Publicacions Universitat de Barcelona, 2003, pp. 745-767; S. GIURATO, La Sicilia di Ferdinando il Cattolico. Tradizioni politiche e conflitto tra Quattrocento e Cinquecento (1468-1523), Mesina, Rubbettino, 2003, p. 168; M. FRÜH, "Antonio Geraldini en el mundo catalano-aragonés de su época: resultados de una tesis doctoral”, en I Geraldini 
di Amelia nell'Europa del Rinascimento. Atti del Convegno Storico Internazionale, Amelia 21-22 novembre 2003, Terni-Amelia, 2004, pp. 65-69; ID., Antonio Geraldini ( +1488$)$ : Leben, Dichtung und soziales Beziehungsnetz eines italienischen Humanisten am aragonesischen Königshof: mit einer Edition seiner "Carmina ad Iohannam Aragonum”, Münster, LIT, 2005, ad indicem, especialmente pp. 108-109; É. RouZIÈs, Lectures médiévales de Salluste, Thèses de l'Ecole nationale des Chartes, París, 2004; G. QUARANTA, "L'intricata vicenda delle origini di Monsignor Francesco Vitali", en Calabria Sconosciuta, 28 (2005), pp. 53-55; R. MADRID Souto, "Francisco Vidal de Noya, embajador del Rey Católico", en M. GonZÁlez JimÉnez y I. Montes RoMero-CAMACHO (eds.), La Península Ibérica entre el Mediterráneo y el Atlántico. Siglos XIII-XV, Diputación de Cádiz-Sociedad Española de Estudios Medievales, Sevilla-Cádiz, 2006, pp. 449-456; Á. FERNÁNDEZ DE Córdova Miralles, "Vidal de Noya, Francisco", en Diccionario Biográfico Español, Real Academia de la Historia, Madrid, 2013, pp. 902-904..

\section{Juan Ruiz de Medina}

FUENTES: Biblioteca de la Real Academia de la Historia (Madrid), Colección Salazar.

BiBliografía: Capítulos y ordenamientos de la Inquisición, Real Biblioteca (Madrid), II/2383 (ff. 59r-70v); D. ORTIZ DE ZúÑIGA, Anales eclesiásticos y seculares de la muy noble y muy leal ciudad de Sevilla, vol. I, Madrid, Imprenta Real, 1795, p. 389; E. Flórez, España Sagrada, vol. XVI: La Iglesia de Astorga, Editorial Revista Agustiniana, Madrid, 2005, pp. 266-268; B. S. CASTEllanos DE LOSADA (dir.), Biografía eclesiástica, vol. XXIV, Madrid, Imprenta de Alejandro Gómez Fuentenebro, 1863, pp. 362-364; G. VoLPI (ed.), La resa di Granata (1492) descritta dall'orator di Castiglia e di Aragona presso la S. Sede dalle carte dell'Archivio di Stato di Lucca, Luca, 1889; C. DE LECEA, "Memorial histórico de Segovia, escrito por don Juan de Pantigoso en 1523", en Boletín de la Real Academia de la Historia, 14 (1889), p. 225; P. DíAZ CASSOU, Serie de los Obispos de Cartagena. Sus hechos y su tiempo, Madrid, 1895, pp. 70-71; C. EubEL, Hierarchia Catholica Medii Aevi, vol. II, Patavii, Il Messaggero di S. Antonio, 1898-1923, pp. 97, 119 y 234; J. BURCKARDT, Liber notarum ab anno 1483 usque ad annum 1506, ed. E. Celani, vol. I, Città di Castello, Editrice S. Lapi, 1907-1942, pp. 159-160, 199, 218, 229, 235 y 424; vol. II, pp. 70-71, 133 y 137; J. AgAPITO y ReVILla, Los retablos de Medina del Campo, Valladolid, Tipografía del Colegio Santiago, 1916, pp. 17-28 y ss; M. ALCOCER MARTíNEZ (ed.), Historia de la Universidad de Valladolid: expedientes de provisiones de cátedras, ordenados y anotados por Mariano Alcocer Martinez, Valladolid, Imprenta Castellana, 1921, p. 412; A. Bernáldez, Memorias del reinado de los Reyes Católicos, ed. de M. Gómez-Moreno y Juan de M. Carriazo, Madrid, Patronato Marcelino Menéndez Pelayo, 1962, p. 99; A. DE LA TORRE Y DEL CERRO, Documentos sobre las relaciones internacionales de los Reyes Católicos, vols. I-V, Barcelona, Consejo Superior de Investigaciones Científicas, 1949-1966, ad indices; L. SuÁrEZ FERNÁNDEZ, Política internacional de Isabel la Católica. Estudio y documentos, vol. II, Valladolid, Universidad de Valladolid, 1966, pp. 485-492; vol. III, 1969, pp. 295-298; vol. IV, 1971, pp.592-596; T. DE AZCONA, La elección y reforma del episcopado español en tiempos de los Reyes 
Católicos, Madrid, Consejo Superior de Investigaciones Científicas, 1960, pp. 156, 162 y 213; ID., Isabel la Católica. Estudio crítico de su vida y reinado, Madrid, Biblioteca de Autores Cristianos, 1993, pp. 390, 526 y 759; R. CARANDE y J. DE M. CARRIAZO (eds.), El Tumbo de los Reyes Católicos del Concejo de Sevilla, vol III: Años 1479-1485, Sevilla, Editorial Católica Española, 1968, pp. 112, 129, 131, 161, 293-294 y 401; D. DE Colmenares, Historia de la insigne ciudad de Segovia y compendio de las historias de Castilla, vol. I, Segovia, Academia de Historia y Arte de San Quirce, 1969, pp. 142-143; vol. II, pp. 158-159; V. BELTRÁn DE HEREDIA, Cartulario de la Universidad de Salamanca, vol. II, Salamanca, Universidad de Salamanca, 1970, p. 55; vol. IV, 1972, p. 565; vol. V, 1972, p. 165; G. Moraleja Pinilla, Historia de Medina del Campo, Medina, Manuel Mateo, 1971, p. 455; M. A. VARONA GARCíA, La Chancillería de Valladolid en el reinado de los Reyes Católicos, Valladolid, Universidad de Valladolid, 1981, p. 300; Má. DE LA S. MARTín Postigo, Los presidentes de la Real Chancillería de Valladolid, Valladolid, Institución Cultural Simancas, 1982, pp. 33-35; H. CH. DE LEA, Historia de la Inquisición española, vol. I, Madrid, Fundación Universitaria Española, 1983, p. 200; J. L. GOTOR LÓPEZ, "Il carme De casu regis di Pietro Martire d'Anghiera e la tragicomedia Fernandus seruatus di Marcellino Verardi”, en ID., Carte spagnole. Dieci saggi di letture e ricerche, Perusa, 1984, p. 8; J. TORRES FONTES, Estampas de la vida murciana en la época de los Reyes Católicos, Murcia, Academia Alfonso X El Sabio, 1984, pp. 341-343; P. FARENGA, Ciscostanze e modi della diffusione dell' "Historia Baetica", en M. CHIABÒ, P. FARENGA y M. Miglio (dirs.), Caroli Verardi. Historia Baetica. La Caduta di Granata nel 1492, Roma, Bibliotheca scriptorum LatinorumRR inedita, 1993, pp. XXIX-XXX; C. GARRIGA, La Audiencia y las Chancillerias castellanas (1371-1525). Historia política, régimen jurídico y práctica institucional, Madrid, Centro de Estudios Constitucionales, 1994, pp. 256 y 272; A. PALENCIA, Guerra de Granada, estudio preliminar de R. G. Peinado Santaella, Granada, Universidad de Granada, 1998, pp. LXXV-XCVII y 260; J. GIL, Los conversos y la Inquisición sevillana, vol. I, Sevilla, Universidad de Sevilla-Fundación El Monte, 2000, pp. 50, 67-69 y 76; S. ANGELI, Legenda volgare di Colomba da Rieti, ed. G. Casagrande, Espoleto, Centro Italiano di Studi sull'Alto Medioevo, 2002, p. 160; M. J. OlivarES TEROL, "Los obispos de la diócesis cartaginense durante el siglo XVI y sus relaciones con el cabildo catedralicio", en Murgetana, 109 (2003), p. 48; Á. FERNÁNDEZ DE CóRDOVA MiRALLES, Alejandro VI y los Reyes Católicos. Relaciones político-eclesiásticas (1492-1503), Roma, Edizioni Università della Santa Croce, 2005, pp. 79-80, 136-138, 163, 175, 263, 403, 610 y 696; ID., "Ruiz de Medina, Juan", en Diccionario Biográfico Español, vol. 44, Real Academia de la Historia, Madrid, 2013, pp. 784-786; ID., y V. CALvo FernándeZ, La muerte del heredero. Liturgia y humanismo por el príncipe Juan en su marco europeo (en preparación); W. H. WoODWARD, Cèsar Borja, Valencia, Tres i Quatre, 2005, p. 82-84; F. CAntatore, San Pietro in Montorio: la chiesa dei Re Cattolici a Roma, Roma, Quasar, 2007, ad indicem; M. BlAnCo CONTANO, "La Catedral de Badajoz, cuna de la educación pacense", en F. TEJAdA Vizuete (dir.), La Catedral de Badajoz, 1255-2005, Badajoz, Tecnigraf, 2007, p. 236; F. VILlASEÑOR SEBASTIÁN, "Juan Ruíz de Medina, regio oratori in romana curia, y un conjunto de sus incunables miniados”, en M. C. Cosmen Alonso, M. V. Herráez Ortega, y M. Pellón Gómez-CAlCERRAdA (coord.), El intercambio artístico entre los reinos hispanos y las cortes europeas en la Baja Edad Media, León, Universidad de León, 2009, pp. 239-252; A. SÁNCHEZ DEL BARRIO (coord.), Fundación Museo de las Ferias. "La Pieza del Mes" 2000-2010, Diputación de Valladolid y Fundación Museo de las 
Ferias, Valladolid, 2011; Civitates: ciudades y comercio en la Europa de los siglos XVI y XVII, Diputación de Valladolid, Medina del Campo, Fundación Museo de las Ferias, 2010, pp. 58-59; M. D. RINCÓN GONZÁLEZ, "La divulgación de la Toma de Granada: objetivos, mecanismos y agentes", en Anuario de estudios medievales, 40-2 (2010), pp. 603-615; R. GONZÁlEZ ARÉVAlO, "Ecos de la toma de Granada en Italia: de nuevo sobre las cartas a Milán y Luca", en, Homenaje al profesor Eloy Benito Ruano, vol. 1, Murcia, 2010, pp. 343353; M. Gamero Rojas, "Istruzioni spagnole", en A. ProsPeri (dir.), Dizionario storico dell'Inquisizione, vol. II, Edizione della Normale, Pisa, 2010, p. 853.

\section{Francisco de Rojas y Escobar}

FuENTES: Biblioteca del Instituto Valencia de don Juan (Madrid), Manuscritos; Correspondencia del Gran Capitán; Biblioteca Francisco Zabálburu y Basabe (Madrid), Altamira; Archivo de la Diputación Provincial de Zaragoza (Zaragoza), Archivo de la Diputación del Reino, Alacena de Zurita; Real Academia de la Historia (Madrid), Colección Salazar y Castro; Historia del pontificado de Alejandro VI hasta 1501, Gerona, Biblioteca del Seminario Diocesano, ms. 12, cap. 366 [Agradezco a Maria Toldrà la consulta de esta preciosa fuente cuya edición está preparando].

BibliografíA: P. DE RojAs, "Elogio de la vida y hechos del embajador D. Francisco de Rojas y Escobar", en Discursos ilustres, históricos y genealógicos, por D. Pedro de Rojas, caballero de la Orden de Calatrava, Conde de Mora, señor de la Villa de Laios y el Castañar, Toledo, Juan Ruiz de Pereda (impresor), 1636, pp. 200r-228v; G. DE LA VEGA (ed.), Carta a los Reyes Don Fernando y Doña Isabel de su embajador en Roma en 1498, San Sebastián, Imprenta de Ignacio Ramón Baroja, 1842, pp. 13-14; A. GIUSTINIAN, Dispacci, ed. P. Villari, vols. I-III, Florencia, Le Monnier, 1876, ad indicem; M. SANUdO, Diarii, vols. II-XIV, ed. R. Fulin, Venecia, 1879-1903, ad indicem; P. DE GRASSIS, Le due spedizioni militari di Giulio II tratte dal Diario di Paride de Grassi bolognese, ed. de L. Frati, Bolonia, 1886, ad indicem; A. F. FITA, "Primeros años del episcopado de América", en Boletín de la Real Academia de la Historia, 20 (1892), pp. 263-272; F. RODRÍGUEZ VILlA, La reina doña Juana la Loca, estudio histórico, Madrid, Libreria de M. Murillo, 1892, ad indicem; ID., "Don Francisco de Rojas, embajador de los Reyes Católicos", en Boletín de la Real Academia de la Historia, 28 (1896), pp. 180-202, 295-339, 364-402 y 440-474; 29 (1896), pp. 5-69; L. I. SERRANO Y PinedA (ed.), "Correspondencia de los Reyes Católicos con el Gran Capitán durante las campañas de Italia", en Revista de Archivos Bibliotecas y Museos, 21 (1909), pp. $441-359$ (serie de artículos hasta) 29 (1912), pp. 300312; ID., "Noticias inéditas del Gran Capitán", en Boletín de la Real Academia de la Historia, 79 (1921), pp. 225-275; ID., "Nuevos datos sobre el Gran Capitán", en Hispania, 3 (1943), pp. 70-88; TORRE, L. DE, y RodríGuez PASCUAL, R. (ed.), “Cartas y documentos relativos al Gran Capitán”, en Revista de Archivos Bibliotecas y Museos, 34 (1916), pp. 300316; (serie de artículos hasta) 44 (1923), pp. 389-405; DUQUE DE BERWICK Y DE ALBA, Correspondencia de Gutierre Gómez de Fuensalida, embajador en Alemania, Flandes e Inglaterra (1496-1509), Madrid, s.n., 1907, ad indicem; J. BURCKARDT, Liber notarum ab anno 1483 usque ad annum 1506, ed. E. Celani, vol. II, Città di Castello, Editrice S. Lapi, 
1907-1942, ad indicem; L. I. SERRANO y PinedA (ed.), "Correspondencia de los Reyes Católicos con el Gran Capitán durante las campañas de Italia", en Revista de Archivos Bibliotecas y Museos, 28 (1913), pp. 385-386; R. RAMÍREZ DE ARELLANO, Las parroquias de Toledo, Toledo, 1921, pp. 10-20; M. BERTOLA, I due primi registri di prestito della Biblioteca apostolica vaticana, codici vaticani latini. 3964, 3966, Ciudad del Vaticano, Biblioteca Apostólica Vaticana, 1942, p. 79; J. M. Doussinague, La política internacional de Fernando el Católico, Madrid, Espasa-Calpe, 1944, pp. 538-541; ID., Fernando el Católico y el cisma de Pisa, Madrid, Espasa Calpe, 1946, ad indicem; Floreto de anécdotas y noticias diversas que recopiló un fraile dominico residente en Sevilla a mediados del siglo XVI, ed. F. J. Sánchez Cantón, en Memorial histórico español, vol. 48, Madrid, Imprenta de la Real Academia de la Historia, 1948, p. 52; J. M. DE AZCÁRATE, Arquitectura gótica toledana del siglo XV, Madrid, Instituto Diego Velázquez, 1958, pp. 30 y 39; T. DE AzCONA, La elección y reforma del episcopado español en tiempos de los Reyes Católicos, Madrid, Consejo Superior de Investigaciones Científicas, 1960, ad indicem; ID., "Relaciones de Inocencio VIII con los Reyes Católicos, según el fondo Podocataro de Venecia", en Hispania Sacra, 32 (1980), pp. 7-8; ID., Isabel la Católica. Estudio crítico de su vida y reinado, Madrid, Biblioteca de Autores Cristianos, 1993, ad indicem; J. MANGLANO Y CuCAlo de Montull (Barón de Terrateig), Política en Italia del Rey Católico (1507-1516). Correspondencia inédita con el embajador Vich, vol. I-II, Madrid, Consejo Superior de Investigaciones Científicas, 1963, ad indicem; A. DE LA TORRE Y DEL CERRO, Documentos sobre las relaciones internacionales de los Reyes Católicos, vols. II-V, Barcelona, Consejo Superior de Investigaciones Científicas, 1950-1966, ad indices; L. SUÁREZ FERNÁNDEZ, y J. DE M. Carriazo Arroquia, La España de los Reyes Católicos (1474-1515), en Historia de España Menéndez Pidal, t. XVII, vols. I-II, Madrid, Espasa Calpe, 1969, ad indicem; L. SuÁrez Fernández, Política internacional de Isabel la Católica. Estudio y documentos, vols. I-VI, Valladolid, Universidad de Valladolid, 1965-2002; vol. II, pp. 325-331, 378-384, 388-390, 430-431 y 435-438; vol. IV, pp. 416-418, 517 y 591; vol. VI, pp. 85, 194-198, 308-309, 347-348, 385-392 y 447; V. BELTRÁn DE HEREDIA, Cartulario de la Universidad de Salamanca, vols. I-VI, Salamanca, Universidad de Salamanca, 1970-1972, ad indicem; J. C. Gómez Menor, "Los Rojas de Toledo", en Anales Toledanos, 6 (1963), pp. 183-197; A. GARCÍA Y GARCÍA "Nuevos descubrimientos sobre la canonística salmantina del siglo XV", en Anuario de historia del derecho español, 50 (1980), pp. 361-374; F. de B. SAN Román, "La parroquia de San Andrés. Notas históricas", en Toletum: Boletín de la Real Academia de Bellas Artes y Ciencias Históricas de Toledo, (15) 1984, pp. 207-219; P. LÓPEZ PITA, "Las Comunidades frente a Francisco de Rojas", en En la España Medieval, 9 (1986), pp. 591-602; ID., "Francisco de Rojas: embajador de los Reyes Católicos", en Cuadernos de Investigación Histórica, 15 (1994), pp. 99-149; TH. FRENZ, Die Kanzlei der Papste der Hochrenaissance (1471-1527), Roma, Niemeyer, 1989, p. 333 (n. 765); J. GARCÍA ORO, El Cardenal Cisneros: vida y empresas, vol. I, Madrid, Biblioteca de Autores Cristianos, 1992, pp. 171-173; ID., "Francisco de Rojas (1446-1523): apuntes biográficos sobre un diplomático toledano cercano al Cardenal Cisneros", en Archivo ibero-americano, 69/264 (2009), pp. 625-720; F. MARTíNEZ GIL, La ciudad inquieta. Toledo comunera, 1520-1522, Toledo, Instituto Provincial de Investigaciones y Estudios Toledanos, 1993, ad indicem; J. YARZA LuACES, Los Reyes Católicos: paisaje artístico de una monarquía, Madrid, Nerea, 1993, ad indicem; ID., La nobleza ante el rey: los grandes linajes castellanos y el arte en el siglo XV, Madrid, El Viso, 2004, p. 263; J. BACKHOUSE, The Isabella Breviary, Londres, 
The Bristish Library, 1993; J. ZuRITA, Historia del rey don Hernando el Cathólico. De las empresas y ligas de Italia, ed. A. Canellas López, vol. II, Zaragoza, Gobierno de Aragón, 1996, pp. 243 y 295; vol. III, pp. 169, 362-363 y 368; G. T. CLARK, The hours of Isabel la Católica, Madrid, Patrimonio Nacional-Testimonio Compañía Editorial-MünsterBibliotheca Rara, 1997; R. DE ANDRÉS DÍAZ, El último decenio del reinado de Isabel I a través de la tesorería de Alonso de Morales (1495-1504), Valladolid, Universidad de Valladolid, 2004, ad indicem; E. RUIZ GARCÍA, "Los breviarios de la reina católica: un signo de modernidad" en III Jornadas cientificas sobre Documentación en la época de los Reyes Católicos, Madrid, Departamento de CC. Y TT. Historiográficas, 2004, pp. 240-243; Á. Fernández de Córdova Miralles, Alejandro VI y los Reyes Católicos. Relaciones político-eclesiásticas (1492-1503), Roma, Università della Santa Croce, 2005, pp. 49, 81, 95-98, 129-132, 136, 139, 248-253, 425-461, 515, 549, 559-572, 621-626, 639-640, 652653, 671 y 675; ID., "Alejandro VI y los Reyes Católicos. Afinidades y diferencias al final de un pontificado (1498-1503)", en La llum de les imatges (abril-diciembre 2007), Generalitat Valenciana, Valencia, 2007, pp. 281-299; ID., "Cèsar Borja en el seu context històric: entre el pontificat i la monarquia hispànica”, en Id, J. ARRIZABALAGA, y M. TOLDRÀ, Cèsar Borja cinc-cents anys després (1507-2007). Tres estudis $i$ una antologia, Valencia, 2009, pp. 11-98; ID., y C. VILlanUeVA MoRTE, Juan Claver, embajador de los Reyes Católicos en la Italia del Renacimiento (en preparación); ID., Fernando el Católico y Julio II (en preparación); ID., "Los Reyes Católicos ante la elección pontificia de Pío III: la acción negociadora hispana en sede vacante (1503)", en Pere Miquel Carbonell i el seu temps (1434 - 1517), Reial Acadèmia de Bones Lletres de Barcelona (en prensa); ID., Fernando el Católico y Julio II: Papado y Monarquía hispánica a comienzos de la modernidad (en preparación); W. H. WOODWARD, Cèsar Borja, prólogo de J. Benavent y revisión de M. Toldrà, Valencia, Tres i Quatre, 2005, ad indicem; I. CADIÑANOS BARDECI, "Precisiones acerca del Tránsito de la Virgen de Juan Correa de Vivar", Boletín del Museo del Prado, 24-42 (2006), pp. 6-13; A. SERIO, "Una representación de la crisis de la unión dinástica: los cargos diplomáticos en Roma de Francisco de Rojas y Antonio de Acuña (1501-1507)", en Isabel la Católica y su época (Actas del Congreso Internacional, Valladolid-Barcelona-Granada, 2004), Instituto Universitario de Historia Simancas, Valladolid, 2007, vol. II, pp. 849-862; J. M. MARTín GARCÍA, "Rojas y Escobar, Francisco de”, Diccionario Biográfico Español, vol. 44, Real Academia de la Historia, Madrid, 2013, pp. 230-232. 